\title{
A Novel Combined Scientific and Artistic Approach for the Advanced Characterization of Interactomes: The Akirin/Subolesin Model
}

\author{
Sara Artigas-Jerónimo ${ }^{1,+}+\mathbb{D}$, Juan J. Pastor Comín ${ }^{2,+} \mathbb{D}$, Margarita Villar $1,+, \ddagger \mathbb{D}$, \\ Marinela Contreras ${ }^{1,+}\left(\mathbb{D}\right.$, Pilar Alberdi ${ }^{1}\left(\mathbb{D}\right.$, Israel León Viera ${ }^{3}$, Leandro Soto ${ }^{4}$, Raúl Cordero ${ }^{5}$, \\ James J. Valdés ${ }^{6,7,8}$, Alejandro Cabezas-Cruz ${ }^{9}$ (D) Agustín Estrada-Peña ${ }^{10}$ and \\ José de la Fuente $1,11, * \mathbb{D}$
}

1 SaBio. Instituto de Investigación en Recursos Cinegéticos IREC-CSIC-UCLM-JCCM, Ronda de Toledo s/n, 13005 Ciudad Real, Spain; sartigasjeronimo@gmail.com (S.A.-J.); margaritam.villar@uclm.es (M.V.); marinelacr@hotmail.com (M.C.); maria.alberdi@uclm.es (P.A.)

2 Centro de Investigación y Documentación Musical CIDoM-UCLM-CSIC, Facultad de Educación de Ciudad Real, Ronda Calatrava 3, 13071 Ciudad Real, Spain; juanjose.pastor@uclm.es

3 León Viera Studio, Calle 60 No. 338 M por 31, Colonia Alcalá Martín, Mérida 97000, Mexico; leonvieraisrael@gmail.com

4 Artesadhana Studio, Mérida 97000, Mexico; sotoananda@gmail.com

5 Raúl Cordero Studio, Calle Rio Elba 21-8, Colonia Cuauhtémoc, CDMX 06500, Mexico; raulcorderostudio@gmail.com

6 Faculty of Science, University of South Bohemia, 37005 České Budějovice, Czech Republic; valdjj@gmail.com

7 Institute of Parasitology, Biology Centre, Czech Academy of Sciences, Branišovská 1160/31, 37005 České Budějovice, Czech Republic

8 Department of Virology, Veterinary Research Institute, Hudcova 70, 62100 Brno, Czech Republic

9 UMR BIPAR, INRA, ANSES, Ecole Nationale Vétérinaire d'Alfort, Université Paris-Est, Maisons-Alfort 94700, France; cabezasalejandrocruz@gmail.com

10 Facultad de Veterinaria, Universidad de Zaragoza, 50013 Zaragoza, Spain; aestrada@unizar.es

11 Department of Veterinary Pathobiology, Center for Veterinary Health Sciences, Oklahoma State University, Stillwater, OK 74078, USA

* Correspondence: jose_delafuente@yahoo.com

+ These authors contributed equally to this work.

$\ddagger$ Present address: Biochemistry Section, Faculty of Science and Chemical Technologies, and Regional Centre for Biomedical Research (CRIB), University of Castilla-La Mancha, 13071 Ciudad Real, Spain.

Received: 7 January 2020; Accepted: 7 February 2020; Published: 8 February 2020

check for updates

\begin{abstract}
The main objective of this study was to propose a novel methodology to approach challenges in molecular biology. Akirin/Subolesin (AKR/SUB) are vaccine protective antigens and are a model for the study of the interactome due to its conserved function in the regulation of different biological processes such as immunity and development throughout the metazoan. Herein, three visual artists and a music professor collaborated with scientists for the functional characterization of the AKR2 interactome in the regulation of the NF- $\mathrm{B}$ p pathway in human placenta cells. The results served as a methodological proof-of-concept to advance this research area. The results showed new perspectives on unexplored characteristics of AKR2 with functional implications. These results included protein dimerization, the physical interactions with different proteins simultaneously to regulate various biological processes defined by cell type-specific AKR-protein interactions, and how these interactions positively or negatively regulate the nuclear factor kappa-light-chain-enhancer of activated B cells (NF- $\mathrm{KB}$ ) signaling pathway in a biological context-dependent manner. These results suggested that $A K R 2$-interacting proteins might constitute suitable secondary transcription factors for cell- and stimulus-specific regulation of NF- $\kappa$ B. Musical perspective supported AKR/SUB evolutionary conservation in different species and provided new mechanistic insights into the AKR2
\end{abstract}


interactome. The combined scientific and artistic perspectives resulted in a multidisciplinary approach, advancing our knowledge on AKR/SUB interactome, and provided new insights into the function of AKR2-protein interactions in the regulation of the NF- $\kappa B$ pathway. Additionally, herein we proposed an algorithm for quantum vaccinomics by focusing on the model proteins AKR/SUB.

Keywords: akirin; subolesin; interactome; art; evolution; music; yeast two-hybrid; NF-кB; vaccine; quantum vaccinomics; protective epitope

\section{Introduction}

Biology and art have collaborated before for communication in areas such as human physiology and evolution [1-4], even proposing that art may have biological basis [5]. As scientists, art reminds us of the power of curiosity, which frequently gets lost during research, and asks questions that are relevant for investigation, thus supporting the fact that science benefits when artists get involved in research [6,7]. Art visual and musical representations translate into complex or unrecognized concepts and provide a way to better understand and approach scientific challenges [8-10]. Art also contributes to highlighting social concerns addressed by scientists [4]. In this way, art and science converge in the purpose of moving society forward, and both benefit from the learning process [9-11].

In this study, we provided a perspective of the combined scientific and artistic approach to the interactome using as a model the regulatory protein Akirin, from the Japanese "akiraka ni suru" meaning "making things clear" (AKR; also known as Subolesin (SUB) in ticks). AKR/SUB were first identified in Drosophila melanogaster, Mus musculus, and Ixodes scapularis as transcription factors involved in the regulation of immune deficiency (IMD) and tumor necrosis factor (TNF)/Toll-like receptor (TLR)-nuclear factor kappa-light-chain-enhancer of activated B cells (NF-kB) (TNF/TLR) signaling pathways, and developmental processes [12-15]. Recent results have shown that AKR/SUB evolved with conserved sequence and structure, suggesting a functional role in cell interactome and regulome in response to pathogen infection and other stimuli [16-18]. Additionally, AKR/SUB have shown protection in vaccines for the control of multiple ectoparasite infestations and pathogen/infection transmission [17]. Therefore, AKR/SUB constitute a good model for the study of structural, functional, and evolutionary biology due to their conserved function in the regulation of different biological processes throughout the metazoan [16-18]. However, differences in results available on the AKR interactome and its functional implications pose a challenge for the understanding of the function of this protein [17-28]. For example, it is unknown how AKR/SUB-protein interactions regulate signaling pathways such as the NF-kB involved in the regulation of immune response.

To address this question, herein we proposed a novel methodology to approach challenges in molecular biology using as a model the characterization of the AKR2 interactome and its functional role in the regulation of the NF-kB signaling pathway in human placenta cells. The results of this approach advanced our knowledge in this area by showing that AKR/SUB protein dimerization/multimerization and the physical interactions with different proteins simultaneously are involved in the regulation of various biological processes defined by cell type-specific AKR2-protein interactions and the role of these interactions in the positive and negative regulation of the NF-kB pathway.

The characterization of protein-protein interactions and vaccinomics have been proposed as novel approaches for vaccine development [29]. Considering the structural and functional conservation of AKR/SUB proteins [17], the characterization of the AKR2 interactome may have implications in quantum vaccinomics as a new approach for the development of vaccines for the control of vector infestations and infection/transmission of vector-borne pathogens. In this context, quantum vaccinomics could be focused on cell interactome and regulome for the identification of protective epitopes in peptide sequences involved in protein-protein interactions or selected interacting domains (SID) that are particularly relevant for proteins such as AKR/SUB that function through these interactions. 


\section{Materials and Methods}

\subsection{Approaching Collaboration between Visual and Musical Artists and Scientists}

The methodological approach used in this study consisted of collaborations between artists and scientists to address questions in the molecular biology of interactomes using the regulatory factor AKR/SUB as a model. Three visual artists, Israel León Viera, Leandro Soto, and Raúl Cordero were selected for participating in this project. Israel León Viera and Leandro Soto participated in a leading art group known as "Volumen Uno" (Volume One) who challenged artistic establishment in Cuba in the 1980s, and have shown a continued interest in social, historical, and cultural subjects [30]. Raúl Cordero is an artist with an interest in science and technical challenges in visual art and communication [31]. These artists were invited to read a simplified version of our recent review on AKR/SUB functional evolution [17], with special attention paid to the figures included in the paper. The artists were posed with the challenge that these model proteins represent based on their conserved function in the regulation of different biological processes throughout the metazoan [16-18]. Artists and scientists were in contact to exchange information regarding these proteins and to address artists' questions. In response to this challenge, the artists contributed the pieces and interpretations shown in the paper to provide their view on this matter. Then, these pieces served to inspire scientists to discuss and find new perspectives on unexplored characteristics of these proteins with putative functional implications. A professor of music and musical education was also invited to participate in this research to further develop and apply a musical algorithm developed by us back in 1995 to the study of AKR evolution [8]. The results of these musical representations served to inspire scientists to propose the possibility of using this approach to further characterize AKR-protein interactions, which was faced by the artist resulting in additional support for the results presented in the paper.

\subsection{Yeast Two-Hybrid $Y 2 H$ Screening for the Identification of Human AKR2 Interacting Proteins}

The ULTImate Y2H screening was performed by Hybrigenics Services (Paris, France; www. hybrigenics-services.com) following previously described methods [32,33]. The human AKR2 (amino acids 1-203; Uniprot ID Q53H80) bait was PCR-amplified, sequenced, cloned in the pB27 (N-LexA-AKR2-C fusion) vector, and used for screening using a human placenta RP6 fragment library as prey. In the test screen, we found that the bait did not autoactivate the system, but it was inducing too much signal. Therefore, we used a medium containing $10 \mathrm{mM}$ of 3-amino-1,2,4-triazole (3-AT), a competitive inhibitor of the HIS3 reporter gene product. A total of 330 prey fragments of the positive clones were amplified by PCR and sequenced at their $5^{\prime}$ and $3^{\prime}$ junctions. The resulting sequences were used to identify the corresponding interacting proteins in the GenBank database (NCBI) using a fully automated procedure.

\subsection{Interaction Confidence Scoring}

A confidence score for Predicted Biological Score (PBS) was attributed to each interaction as previously described [33] (Data S1). The PBS score represents the probability of an interaction being non-specific and is computed to assess the interaction reliability. PBS is an e-value, primarily based on the comparison between the number of independent prey fragments found for an interaction and the chance of finding them at random (background noise). The value in the scores $\mathrm{A}$ to $\mathrm{D}$ varies between 0 and $1\left(\mathrm{~A}<1 \mathrm{e}^{-10}<\mathrm{B}<1 \mathrm{e}^{-5}<\mathrm{C}<1 \mathrm{e}^{-2.5}<\mathrm{D}<1\right)$. Several thresholds were arbitrarily defined in order to rank the results in the following scores:

- A: Very high confidence in the interaction.

- B: High confidence in the interaction.

- C: Good confidence in the interaction.

- D: Moderate confidence in the interaction. This category is the most difficult to interpret because it mixes two classes of interactions: (i) false-positive interactions and (ii) interactions hardly 
detectable by the $\mathrm{Y} 2 \mathrm{H}$ technique (e.g., low representation of the mRNA in the library, prey folding, prey toxicity in yeast).

- $\quad$ E: Interactions involving highly connected (or relatively highly connected) prey domains, warning of non-specific interaction. The total number of screens performed on each organism is taken into account to set this connectivity threshold to 20 interactions to different bait proteins in the entire human database. They can be classified in different categories: (i) prey proteins that are known to be highly connected due to their biological function and (ii) proteins with a prey interacting domain that contains a known protein interaction motif or a biochemically promiscuous motif.

- F: Experimentally proven technical artifacts.

- N/A: The PBS is a score that is automatically computed through algorithms and cannot be attributed for the following reasons: (i) all the fragments of the same reference coding sequence (CDS) are antisense, (ii) the $5 \mathrm{p}$ sequence is missing, (iii) all the fragments of the same reference CDS are either all out of frame (OOF1 or OOF2), and (iv) all the fragments of the same reference CDS lie in the $5^{\prime}$ or $3^{\prime}$ untranslated region (UTR).

\subsection{Annotation of Identified AKR2-Interacting Proteins}

DomSight (Hybrigenics Services) was applied to compare the bait fragment and the selected interacting domain (SID) of the prey proteins with the functional and structural domains generated by Pfam (https://pfam.xfam.org), SMART (http://smart.embl-heidelberg.de), TMHMM (http://www. cbs.dtu.dk/services/TMHMM/), SignalP (http://www.cbs.dtu.dk/services/SignalP/), and COILS (https: //embnet.vital-it.ch/software/COILS_form.html) algorithms (Figure S1). N/A annotations (Data S1) were not considered as interactions. Annotations for biological process and subcellular localization were performed according to Uniprot (https://www.uniprot.org; searched on October 2018). Comparison with previously published datasets for AKR2-interacting proteins were performed using datasets for human AKR2 (http://www.humanmine.org/humanmine/portal.do?externalids=55122\&class=Gene\&origin= FlyMine) [19-23]. For validation, AKR2-protein interactions were searched in the public databases STRING (https://string-db.org/cgi/input.pl?sessionId=BIqHpYhivYPx\&input_page_show_search= on) and NCBI (https://www.ncbi.nlm.nih.gov/gene?Db=gene\&Cmd=DetailsSearch\&Term=55122) reporting interactions using alternative interactome models such as ingenuity pathway analysis (IPA).

\subsection{Corroboration of AKR2-Protein Interactions by Protein Pull-Down}

First, the human AKR2-protein interactions identified by $\mathrm{Y} 2 \mathrm{H}$ with very high (A-score) and high (B-score) PBS were used to corroborate these interactions in vitro. Recombinant human (Myc (EQKLISEEDL)-DDK-tagged) AKR2 (Q53H80; RC200881, OriGene, Rockville, MD, USA) was used for interactions with the identified AKR interacting recombinant proteins AKR2, actin related protein 10 (ACTR10; Q9NZ32; H00055860-P01, Novus Biologicals, Littleton, CO, USA), estrogen-related receptor gamma (ESRRG; P62508; ab152371, Abcam, Cambridge, United Kingdom), phosphatidylinositol transfer protein alpha isoform (PITPNA; Q00169; ab101666, Abcam), RING finger protein 10 (RNF10; Q8N5U6; H00009921-P01, Novus Biologicals), splicing factor 3a subunit 1 (SF3A1; Q15459; ab160931, Abcam), and mediator of RNA polymerase II transcription subunit 16 (THRAP5/MED16; Q9Y2 × 0; ab132365, Abcam). Additionally, interferon regulatory factor 6 (IRF6; O14896; ab132057, Abcam) and protein Wnt-2 (WNT2; P09544; ab152803, Abcam) with moderate confidence (D-score) PBS were included in the analysis. The U1 small nuclear ribonucleoprotein $70 \mathrm{kDa}$ (SNRNP70; P08621; H00006625-P01, Abnova GmbH, Heidelberg, Germany) with score F (experimentally proven technical artifact) was included as a negative control. Interacting proteins were incubated with AKR2 for $2 \mathrm{~h}$ and then for 30 min with c-Myc magnetic beads (c-Myc-Tag IP/Co-IP kit, Thermo Fisher Scientific, Waltham, MA, USA) specific for the AKR2 protein tag following the manufacturer's recommendations. A negative control was also performed, incubating only the interacting proteins with the c-Myc magnetic beads. Both incubations were performed with shaking at room temperature (RT). After immunoprecipitation, protein complexes were eluted using Laemmli sample buffer, and the supernatants were used for 
Western blot analyses. Supernatants derived from AKR2-protein interactions and negative controls, together with positive control recombinant protein were run and separated by electrophoresis in a $12 \%$ sodium dodecyl sulfate (SDS) polyacrylamide precast gel (ClearPage, Cole-Parmer, Vermon Hills, IL, USA) and stained with Bio-Safe Coomassie Stain (Bio-Rad Laboratories, Hercules, CA, USA) or transferred to a nitrocellulose blotting membrane (GE Healthcare Life Sciences, Pittsburgh, PA, USA). The membrane was blocked with 3\% bovine serum albumin (BSA) (Sigma-Aldrich, St. Louis, MO, USA) in Tris-buffered saline (TBS; $150 \mathrm{mM} \mathrm{NaCl}, 50 \mathrm{mM}$ Tris- $\mathrm{HCl}, \mathrm{pH} 7.5$ ) for $2 \mathrm{~h}$ at $\mathrm{RT}$ and washed four times with TBS-Tween 20 (150 mM NaCl, 50 mM Tris-Cl, pH 7.5, 0.05\% Tween 20). Different interacting protein-specific primary rabbit or mouse antibodies were used for ACTR10 (mouse H00055860-B01P, Novus Biologicals, 1:500), ESRRG (mouse ab171816, Abcam, 1 g/mL), PITPNA (rabbit ab96519, Abcam, 1:500), RNF10 (mouse H00009921-B01P, Novus Biologicals, 1:500), SF3A1 (rabbit ab69903, Abcam, $0.25 \mu \mathrm{g} / \mathrm{mL}$ ), THRAP5/MED16 (rabbit ab130996, Abcam, 1:2000), SNRNP70 (rabbit VPA00459, Bio-Rad Laboratories, 1:1000), IRF6 (mouse ab123880, Abcam, 1:1000), AKR2 (rabbit ab221475, Abcam, 1:1000), and WNT2/IRP (rabbit ab27794, Abcam, $2 \mu \mathrm{g} / \mathrm{mL}$ ). Antibodies were diluted in TBS and incubated with membranes overnight at $4{ }^{\circ} \mathrm{C}$. Goat anti-mouse or anti-rabbit immunoglobulin (IgG) (whole molecule) peroxidase antibody (Sigma-Aldrich) 1:1000 diluted in TBS with 3\% BSA were used as secondary antibodies and incubated with membranes for $2 \mathrm{~h}$ at RT. The membranes were finally washed five times with TBS-Tween 20, and immunoreactive proteins were visualized with chemiluminescence by incubating the membranes for 2 min with Pierce ECL Western blotting substrate (Thermo Fisher Scientific). In order to identify unrelated proteins eluted from the c-Myc magnetic beads, a similar experiment was conducted with selected proteins ESRRG and RNF10 but incubating only with the secondary antibody. Additionally, c-Myc magnetic beads alone were eluted using Laemmli sample buffer and the supernatant analyzed by SDS-PAGE stained with Bio-Safe Coomassie Stain.

\subsection{In Vitro Characterization of $A K R-A K R$ Protein Interactions}

Recombinant I. scapularis AKR/SUB (Q4VRW2) and B7PDL0 negative control proteins were produced in Escherichia coli using the Champion pET101 Directional TOPO Expression kit (Invitrogen, Carlsbad, CA, USA), as previously described [34,35]. These proteins and human AKR2 (Q53H80) were used for the in vitro characterization of protein-protein interactions. For interactions, $5 \mu \mathrm{g}$ of each protein was incubated in $20 \mu \mathrm{l}$ PBS with shaking at $4{ }^{\circ} \mathrm{C}$ overnight. Then, the proteins were analyzed by electrophoresis under non-denaturing conditions in $12 \%$ polyacrylamide precast gels (Bio-Rad Laboratories, Inc., Hercules, CA, USA) and stained with Coomassie-blue. Precision Plus Protein Standard (Bio-Rad Laboratories, Inc.) was used as molecular weight marker. For Western blot analysis, $10 \mu \mathrm{g}$ of the interactions ( $5 \mu \mathrm{g}$ of each interacting protein) were separated as before, and were transferred to a nitrocellulose membrane. The membrane was blocked with 5\% BSA (Sigma-Aldrich) for $2 \mathrm{~h}$ at RT and washed three times with TBS (50 mM Tris- $\mathrm{HCl}, \mathrm{pH} 7.5,150 \mathrm{mM} \mathrm{NaCl}, 0.5 \%$ Tween 20). Rabbit IgG against tick SUB were used as primary antibodies at a 1:300 dilution in TBS, and the membrane was incubated overnight at $4{ }^{\circ} \mathrm{C}$ and washed three times with TBS. The membrane was then incubated with an anti-rabbit IgG-horseradish peroxidase (HRP) conjugate (Sigma-Aldrich) diluted 1:1000 in TBS with 3\% BSA. The membrane was washed four times with TBS and finally developed with TMB (3,3', 5,5'-tetramethylbenzidine)-stabilized substrate for HRP (Promega, Madrid, Spain) according to the manufacturer's recommendations.

Size exclusion chromatography (SEC) was performed to provide additional support for AKR2-AKR2 and SUB-SUB interactions. The SEC experiment was conducted using the GE AKTA Prime Plus FPLC System (GE Healthcare Life Sciences, Chicago, IL, USA) and the HiPrep 16/60 Sephacryl S-100 HR column (GE Healthcare Life Sciences, 17-1165-01) following the manufacturer's recommendations for size exclusion chromatography (https://www.sigmaaldrich.com/content/dam/ sigma-aldrich/docs/Sigma-Aldrich/General_Information/1/ge-size-exclusion-chromatography.pdf). A calibration curve was prepared using the gel filtration calibration kit (GE Healthcare Life Sciences) with conalbumin $(\mathrm{C} ; 75 \mathrm{kDa})$, ovalbumin $(\mathrm{O} ; 44 \mathrm{kDa})$, carbonic anhydrase (CA; $29 \mathrm{kDa})$, ribonuclease A (R; 
$13.7 \mathrm{kDa})$, and aprotinin (Apr; $6.5 \mathrm{kDa}$ ) proteins to calculate the partition coefficient (Kav) following the manufacturer's protocol $(\mathrm{Kav}=\mathrm{Ve}-\mathrm{Vo} / \mathrm{Vc}-\mathrm{Vo}$, where $\mathrm{Ve}$ is the determined elution volume, $\mathrm{Vo}$ is the void volume $=36 \mathrm{~mL}$, and $\mathrm{Vc}$ is the geometric column volume $=120 \mathrm{~mL}$ ). The equation of the resulting calibration curve $\left(R^{2}=0.97\right)$ was protein molecular weight $(\mathrm{MW})=166086 \mathrm{e}^{-3.377 \mathrm{Kav}}$. Individual proteins were injected separately for calibration in $0.5 \mathrm{~mL}$ sample injection volume $(140 \mathrm{ng} / \mathrm{mL}$ protein concentration in $50 \mathrm{mM}$ sodium phosphate, $150 \mathrm{mM}$ sodium chloride, $\mathrm{pH} 7.2$ ) at a flowrate of $0.8 \mathrm{~mL} / \mathrm{min}$. Recombinant AKR2 $(30 \mathrm{kDa})$ and SUB $(28 \mathrm{kDa})$ were incubated in PBS overnight at $4{ }^{\circ} \mathrm{C}$ before dilution in the column buffer for analysis.

\subsection{Prediction Models of Protein-Protein Binding Sites and Structure}

The proteins with a PBS of A, THRAP5 (Q9Y2X0), and RNF10 (Q8N5U6) were selected to model interactions with AKR2 (Q53H80). Human interferon alpha 1 (IFN-a1; P01562) was used as a negative control protein. For human AKR2 and I. scapularis tick, AKR/SUB (Q4VRW2), AKR2-AKR2, and SUB-SUB interactions were also modeled. Predictions were made using the iFrag server (http://sbi.imim.es/web/index.php/research/servers/iFrag?) [36] at default settings except for e-value $\geq 10$ and identities $\geq 10$. Protein structure models were obtained from The Protein Model Portal for RNF10 (https://www.proteinmodelportal.org/query/uniprot/Q8N5U6) and THRAP5 (https://www. proteinmodelportal.org/query/uniprot/Q9Y2X0).

\subsection{Musical Scores and Ensembles}

The algorithm used to translate DNA coding sequences into music was as previously reported [8], except that each codon was metrically equivalent to a bar and had a differentiated rhythmic and melodic character. The modified algorithm provides for each codon either a constant base of a note on which one or two more notes may follow, or a base of two musical notes followed by one or two more. We provided a ternary structure (three beats of a quarter note) and a binary subdivision measure (3/4), where the base of a single note occupies the entire measure (UGC $=\underline{T}$, dotted-half-note (underlined base)), and the base of two notes was expressed as a half-plus-quarter-note $(\mathrm{CAA}=\underline{\mathrm{MF}})$. If the base is a single note accompanied by others, we always chose to extend the base in the first two beats of the measure as half-note when it had the succession of a single note (UCG $=\underline{\text { SR }}$ half-plus-quarter-note) or two notes (UCC $=$ SMR, half-plus-two-eighth notes). If the base was of two notes, we established for its expression a different metrical scheme: dotted-quarter-note-plus-eighth-note followed by a quarter-note (GCG $=\underline{D R R})$, or by two eighth-notes (GCC $=\underline{D R M R})$. When the algorithm provided the same melodic formula for a double base $(\mathrm{GGA}=\underline{\mathrm{SL}} ; \mathrm{GGC}=\underline{\mathrm{SLDR}})$ and for a single base $(\mathrm{UCA}=\underline{\mathrm{S}} ; \mathrm{UCU}=\underline{\mathrm{SL}})$, we opted for the metric scheme half-plus-quarter-note in the first case and dotted-quarter-note-plus-dotted-quarter-note in the second case. In this way, each codon had a unique rhythmic and melodic definition. All sound files and scores were prepared using the Finale (v. 2018) program (https://www.finalemusic.com). Finding the best match by trial and error produced musical ensembles. Audio files were uploaded and can be found at https://freesound.org/people/josedelafuente/sounds/478998 to 479009 .

\subsection{NF- $\kappa B$ Reporter Assay}

The NF-kB reporter kit (BPS Bioscience, San Diego, CA, USA) was used following the manufacturer's recommendations for monitoring the activity of the NF- $\mathrm{KB}$ signaling pathway in human Hs795.PI (ATCC CRL-7526) placenta cultured cells maintained in Dulbecco's Modified Eagle's Medium (DMEM) medium supplemented with 10\% fetal bovine serum (Thermo Fisher Scientific). The reporter contained a firefly luciferase gene under the control of multimerized NF- $k B$-responsive element located upstream of a minimal promoter. The NF- $\mathrm{kB}$ reporter and a non-inducible firefly luciferase vector were premixed with constitutively expressing Renilla luciferase vector, which served as an internal control for transfection efficiency. To obtain the normalized luciferase activity for NF- $\mathrm{kB}$ reporter, the background luminescence was subtracted and then the ratio of firefly luminescence from the NF- $\mathrm{kB}$ reporter to Renilla luciferase vector control was calculated and used for analysis. 


\subsection{Gene Knockdown by RNA Interference (RNAi)}

The ON-TARGETplus Human Gene SMARTpool small interfering RNAs (siRNAs) $(n=4$ per gene) were designed and synthesized by Dharmacon, Inc. (Lafayette, CO, USA) for $A K R 2$ and the interacting protein coding genes AKR1, RNF10, WNT2, IRF6, THRAP5, and ESRRG. Transfection of human placenta-cultured cells with siRNAs for single or combined gene targets was performed for $24 \mathrm{~h}$.

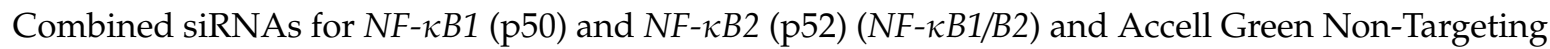
siRNAs (Dharmacon, Inc.) were used as positive and negative control, respectively. Each gene knockdown experiment was performed in both human placenta cells transfected with the NF- $\mathrm{kB}$ luciferase reporter vector and the non-inducible luciferase vector by incubating cells with $25 \mathrm{nM}$ of siRNAs diluted in serum-free medium and Lipofectamine 300 (Invitrogen) in 96-well plates using 6 wells per treatment and following the manufacturer's recommendations. After $24 \mathrm{~h}$, the Dual Luciferase (Firefly-Renilla) Assay System (BPS Bioscience) was performed following the manufacturer's protocol. Luciferase luminescence lecture (kinetic duration $15 \mathrm{~s}$, interval time $2 \mathrm{~s}$, integration time 1 s) was determined using a Tecan Infinite M200 lector (Mannedorf, Switzerland). Background luminescence was subtracted and then the ratio of firefly luminescence from the NF- $\mathrm{kB}$ reporter to Renilla luciferase vector control was calculated and used for analysis. The normalized luciferase activity for NF- $\kappa$ B reporter was compared between groups by Student's $t$-test with unequal variance and by one-way ANOVA (https://www.socscistatistics.com/tests/anova/default2.aspx) $(p=0.05 ; n=6$ biological replicates). After luciferase detection, cells were collected for RNA extraction for analysis of mRNA levels by qRT-PCR. Normalized Ct values were compared between test siRNA-treated placenta cells and controls treated with non-targeting siRNA by Student's $t$-test with unequal variance $(p=0.05$; $n=6)$.

\subsection{Treatment of Human Placenta Cells with Lipopolysaccharides (LPS)}

Human placenta cells were treated with $10 \mu \mathrm{g} / \mathrm{mL}$ of LPS from Salmonella enterica serotype typhimurium (L6143; Sigma-Aldrich) in a 24-well plate using 6 wells per treatment. LPS-treated and PBS-treated control cells were harvested after $24 \mathrm{~h}$ of treatment. Total RNA was extracted from placenta cells using TriReagent (Sigma-Aldrich) following the manufacturer's recommendations and was used to characterize the mRNA levels of AKR2, AKR1, ESRRG, RNF10, THRAP5, IRF6, WNT2, IFN- $\beta$, and IL-6 genes by qRT-PCR. Normalized LPS- to PBS-treated control (C-) Ct values were calculated, and normalized $C t$ values were compared between LPS-treated and C-cells by chi $^{2}$ test $\left({ }^{*} p=0.01 ; n=6\right.$ biological replicates).

\subsection{Analysis of Gene Expression by qRT-PCR}

Total RNA was extracted from placenta cells using TriReagent (Sigma-Aldrich) following the manufacturer's recommendations, and was used to characterize the mRNA levels of selected genes by qRT-PCR using gene-specific oligonucleotide forward (F) and reverse (R) primers (AKR2, F: 5'-CGGAGCCACTCTGAAAAGGA-3', R: 5'-GAGATACTTCTGCGGCGAGG-3'; AKR1, F: 5'-CCCTCCGACAAGTTGGCATA-3'， R: 5'-TAGCTTGTTGGCCTTGTCCC-3'; RNF10, F: 5'-GCTGGAGTATCTGTCTGCCT-3', R: 5'-TCAGTGCAAATGGTCCCCTC-3'; THRAP5,

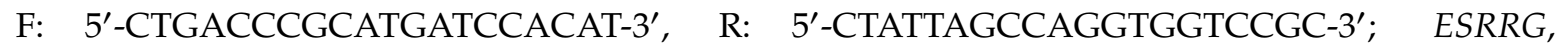
F: 5'-CAGCCAGCCAAAAAGCCATAT-3', R: 5'-TATGCTTCGCCCATCCAATGA-3'; IRF6, F: 5'-GCTCATCTGGCTACACAGGG-3'， R: 5'-AGCTGGGCCTTCCATTTAGC-3'; WNT2, F: 5'-AACCAGGATGGCACAGGTTTC-3', R: 5' -CCTCTCCCACAGCACATGAC-3'; interferon beta IFN- $\beta$, P01574, F: 5'-CGCCGCAGTGACCATCTAT-3' , R: 5' -TCATGCGTTTTCCCCTGGTG-3'; NF- $\kappa B 1$, P19838, F: 5'-AATGGGCTACACCGAAGCAA -3' , R: 5'-CTGTCGCAGACACTGTCACT-3'; NF- $\kappa B 2$, Q00653, F: 5' GCGTTGTCAACCTCACCAAC -3' , R: 5'-GAGTCTCCATGCCGATCCAG-3'; interleukin-6 (IL-6), P05231, F: 5' CCTGAGAAAGGAGACATGTAACAAGA-3', R: 5' GGCAAGTCTCCTCATTGAATCC3'), using the Kapa SYBR Fast One-Step qRT-PCR Kit (Sigma-Aldrich) and the Rotor-Gene Real-Time PCR 
Detection System (Qiagen, Hilden, Germany). A dissociation curve was run at the end of the reaction to ensure that only one amplicon was formed and that the amplicons denatured consistently in the same temperature range for every sample. The mRNA levels were normalized against human $\beta$-actin (F: 5'-CTCGCCTTTGCCGATCC-3; R: 5'-CGCCCACATAGGAATCCTTC-3') using the genNorm Delta-Delta-Ct (ddCt) method as described previously [37].

\subsection{Protein Transfection}

After $24 \mathrm{~h}$ of NF- $\mathrm{kB}$ reporter transfection as described above, human placenta cells were transfected with $0.5 \mathrm{ng}$ proteins per well of AKR2, RNF10, WNT2, IRF6, and combinations with AKR2 using the Pierce Protein Transfection Reagent Kit (Thermo Scientific). Proteins were diluted in HEPES (4-(2-hydroxyethyl)-1-piperazineethanesulfonic acid) buffer (10 mM HEPES, $150 \mathrm{mM} \mathrm{NaCl}, \mathrm{pH} 7.0$ ) and used as solvent for transfection reagent. Transfection reagent/protein complexes were resuspended in serum-free medium and delivered to the cells. After $4 \mathrm{~h}$ of incubation at $37^{\circ} \mathrm{C}$, one volume of $20 \%$ serum-containing medium was added directly to the wells. As a positive control, $0.25 \mu \mathrm{g}$ per well of fluorescein isothiocyanate (FITC)-antibody was transfected following the same protocol. Negative control cells were transfected with $0.5 \mathrm{ng}$ ESRRG protein. After $24 \mathrm{~h}$, the Dual Luciferase (Firefly-Renilla) Assay System (BPS Bioscience) was performed following the manufacturer's protocol. Luciferase luminescence lecture (kinetic duration $15 \mathrm{~s}$, interval time $2 \mathrm{~s}$, integration time $1 \mathrm{~s}$ ) was determined by a Tecan Infinite M200 lector. Background luminescence was subtracted and then the ratio of firefly luminescence from the NF- $\mathrm{kB}$ reporter to Renilla luciferase vector control was calculated and used for analysis. The normalized luciferase activity for NF- $\mathrm{kB}$ reporter was compared between groups by Student's $t$-test with unequal variance ( $p=0.05 ; n=4$ biological replicates). Protein transfection was confirmed in positive control-transfected cells and in comparison with untreated negative control cells by fluorescence microscopy. Cells were mounted in ProLong Antifade with 4'-6-diamidino-2-phenylindole (DAPI) reagent (Molecular Probes, Eugene, OR, USA) and examined using a Zeiss LSM 800 laser scanning confocal microscope (Carl Zeiss, Oberkochen, Germany) with a $63 \times$ oil immersion objective.

\subsection{Prediction and Characterization of AKR/SUB Protective Epitopes}

The identification and prediction of protective linear B-cell epitopes, mimotopes, and conformational discontinuous epitopes were previously described using overlapping oligopeptides scan (pepscan), solution-phase panning with affinity bead capture, and phage-display screening [38]. Protein disorder regions and three-dimensional models were predicted using Disopred [39], Robetta server [40], I-TASSER [41], Lomets [42], Qmean server [43], and FirstGlance in Jmol (http://firstglance.jmol.org), as previously reported $[17,38]$. The design, production, and characterization of $\mathrm{Q} 38$ and $\mathrm{Q} 41$ chimeric antigens based on AKR/SUB protective linear B-cell, mimotopes, and conformational discontinuous epitopes was reported by Moreno-Cid et al. [34]. Protein sequence alignment was performed with human AKR2 (Q53H80), human AKR1 (Q9H9L7), and Ixodes scapularis SUB (Q4VRW2) using the constraint-based multiple alignment tool (COBALT; https://www.ncbi.nlm.nih.gov/tools/cobalt/cobalt. cgi?LINK_LOC=BlastHomeLink).

\section{Results}

3.1. Artist New Perspectives AKR Dimerization and Multiple Simultaneous AKR2-Protein Interactions with Functional Implications

The objective of this study was to provide a multidisciplinary approach complementing scientific and artistic perspectives to address a challenging biological question posed by the functionality of multiple AKR2-protein interactions. Initially, two visual artists were invited to read a simplified version of our recent review on AKR/SUB functional evolution [17]. The artists were posed with the challenge that these model proteins represent based on their conserved function [16-18]. In response to 
this challenge, the artists provided their perspectives on AKR/SUB structure and function. Then, these pieces served to inspire scientists to discuss and find new perspectives on unexplored characteristics of AKR/SUB interactome with putative functional implications. To address this question, a $\mathrm{Y} 2 \mathrm{H}$ screening was performed with the human AKR2 as a LexA-bait fusion in a human placenta cell library, and results were corroborated by in vitro studies and modeling. A professor of music and musical education was also invited to participate in this study to further develop and apply a musical algorithm proposed by us previously to AKR/SUB [8]. The results of these musical representations also led scientists to propose the possibility of using this approach to further characterize AKR-protein functional interactions. Finally, a third visual artist was invited to further contribute to the functional characterization of AKR2-protein interactions in the regulation of the NF- $\mathrm{KB}$ signaling pathway.

In the piece "El Beso" (The Kiss) (Figure 1A), the artist represented protein-protein interactions that appear to play a key role in the evolution and function of AKR/SUB regulatory factors [17]. According to artist's statement, "this piece talks about the origins of life, with multiple geometric images that interact to illustrate in different species the conserved function of these proteins in biological processes represented by the sea, paper boat, Picasso's dove, and a fetus growing in mother's womb while opening the eyes to the world". However, from a scientist's perspective, a new and unexplored facet of possible AKR dimerization was also proposed in this piece (Figure 1A). This structural conformation and its functional implications have not been investigated before. Herein, the results from the $\mathrm{Y} 2 \mathrm{H}$ experiment supported this prediction by showing AKR2-AKR2 and AKR2-AKR1 interactions and confirmed previous reports for AKR2-AKR1 interactions [23] (Figure 1B and Figure S1, Table 1, and Data S1). The SID of AKR1 (aa 132-192) binds to the coiled-coil domain of AKR2 (aa 145-165) and the SID of AKR2 (aa 136-203) binds to the coiled-coil domain of AKR2 (aa 157-177) (Figure 1B). Additionally, in vitro experiments using PAGE and Western blot (Figure 1C,D) or SEC (Figure 1F) and predictive models (Figure 1G) supported AKR-AKR interactions resulting in protein dimerization/multimerization that require attention. 
A

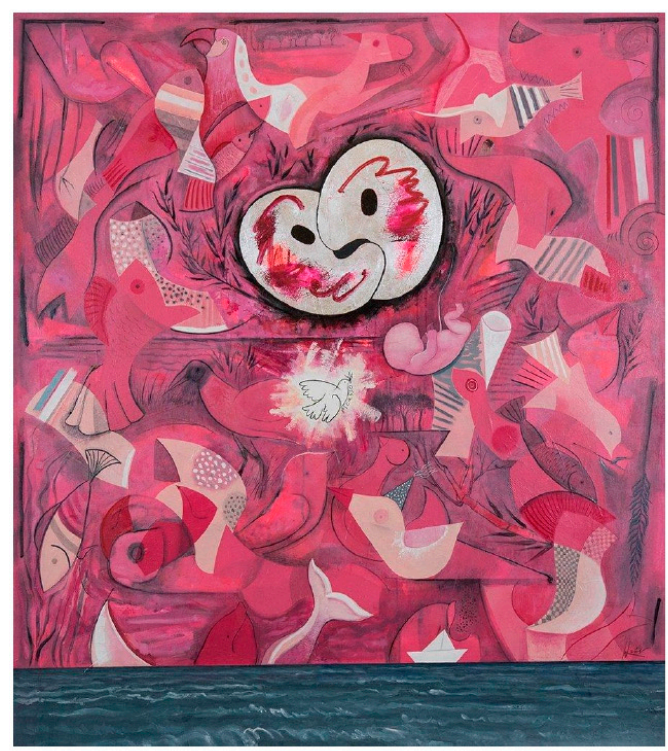

The Kiss: AKR dimerizarion

B

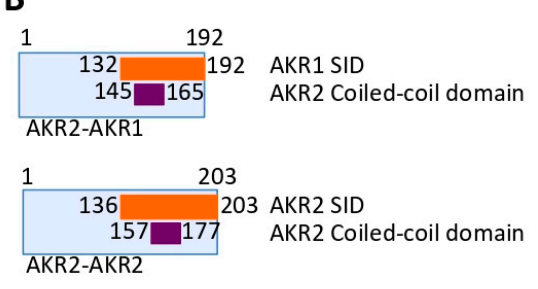

C

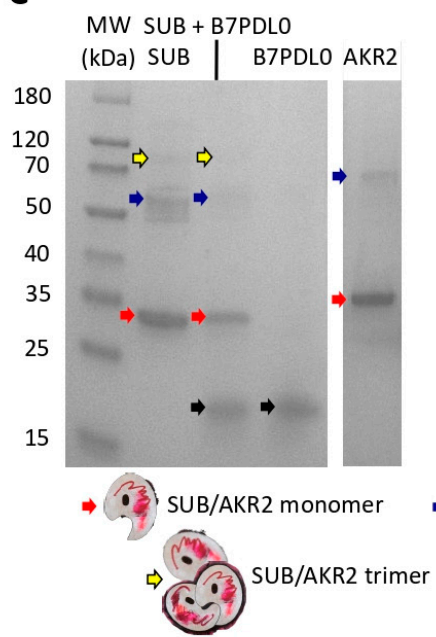

D
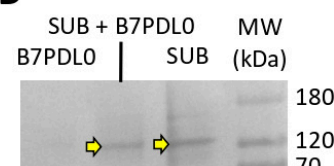

$\Rightarrow \quad 70$
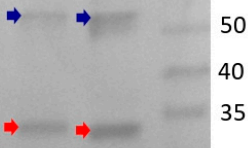

25

5

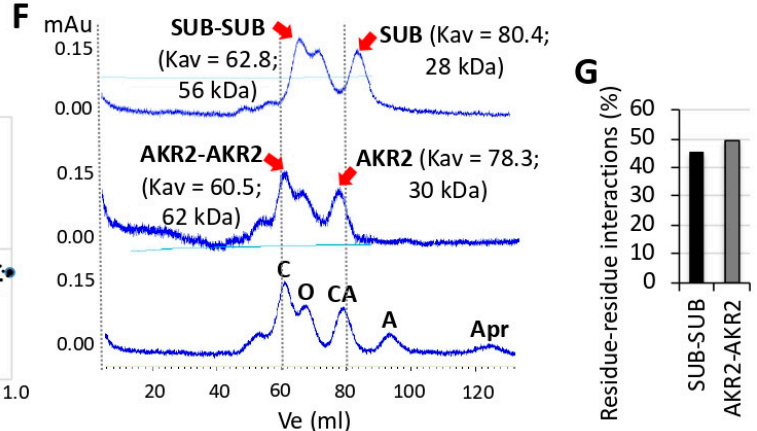

Figure 1. Akirin (AKR) dimerization/multimerization. (A) The piece "El Beso" (The Kiss) by Israel León Viera (mixed media on canvas, 2018, $150 \times 133 \mathrm{~cm}$; dedicated to his daughter Sofía León Jorge; courtesy KGJ Collection, Spain) represents protein-protein interactions that play a key role in AKR function, and a new and unexplored facet of possible AKR dimerization. (B) Protein interacting regions identified by $\mathrm{Y} 2 \mathrm{H}$. SID (selected interaction domain) is the amino acid sequence shared by all prey fragments matching the same reference protein, which have been found to contain structural or functional domains. Only regions containing bait fragments, SIDs, or predicted functional and structural domains were considered. (C,D) In vitro characterization of AKR-AKR protein interactions using Ixodes scapularis SUB (Subolesin; Q4VRW2), human AKR2 (Q53H80), and I. scapularis B7PDL0 negative control. SUB, AKR2, and B7PDL0 were incubated alone and SUB also in combination with B7PDL0 (SUB + B7PDL0), followed by analysis in (C) polyacrylamide gels or (D) Western blot using anti-SUB polyclonal IgG antibodies. (E) Protein gel filtration calibration curve $\left(R^{2}=0.97\right)$ using conalbumin $(\mathrm{C} ; 75 \mathrm{kDa})$, ovalbumin $(\mathrm{O} ; 44 \mathrm{kDa})$, carbonic anhydrase $(\mathrm{CA} ; 29 \mathrm{kDa})$, ribonuclease A (R; $13.7 \mathrm{kDa}$ ), and aprotinin (Apr; $6.5 \mathrm{kDa}$ ). (F) Size exclusion chromatography (SEC) analysis of AKR2 and SUB. The milli absorbance units ( $\mathrm{mAu}$ ) and elution volume (Ve) are shown. The partition coefficient (Kav) and molecular weight (MW) of AKR2/SUB proteins' monomer and dimer were calculated using the equations derived from the calibration curve, $\mathrm{Kav}=\mathrm{Ve}-\mathrm{Vo} / \mathrm{Vc}-\mathrm{Vo}$ and $\mathrm{MW}=166086 \mathrm{e}^{-3.377 \mathrm{Kav}}$. (G) Predicted model of the percentage of amino acids involved in residue-residue interactions for tick SUB-SUB and human AKR2-AKR2 interactions. Predictions were made using the iFrag server (http://sbi.imim.es/web/index.php/research/servers/iFrag?).

The piece "La Danza Molecular" (Molecular Dance) (Figure 2A) also represents protein-protein interactions, which the artist describes according to his words, "the constant movement of these proteins translated into the visual rhythm of repetitive interconnected interactions of forms and colors". Again, in this case the artist suggested a new structural and functional component of AKR/SUB, which from a scientist's perspective translates into the possibility that AKR/SUB physically interacts with 
different proteins simultaneously to regulate various biological processes defined by cell-specific AKR-protein interactions (Figure 2A).
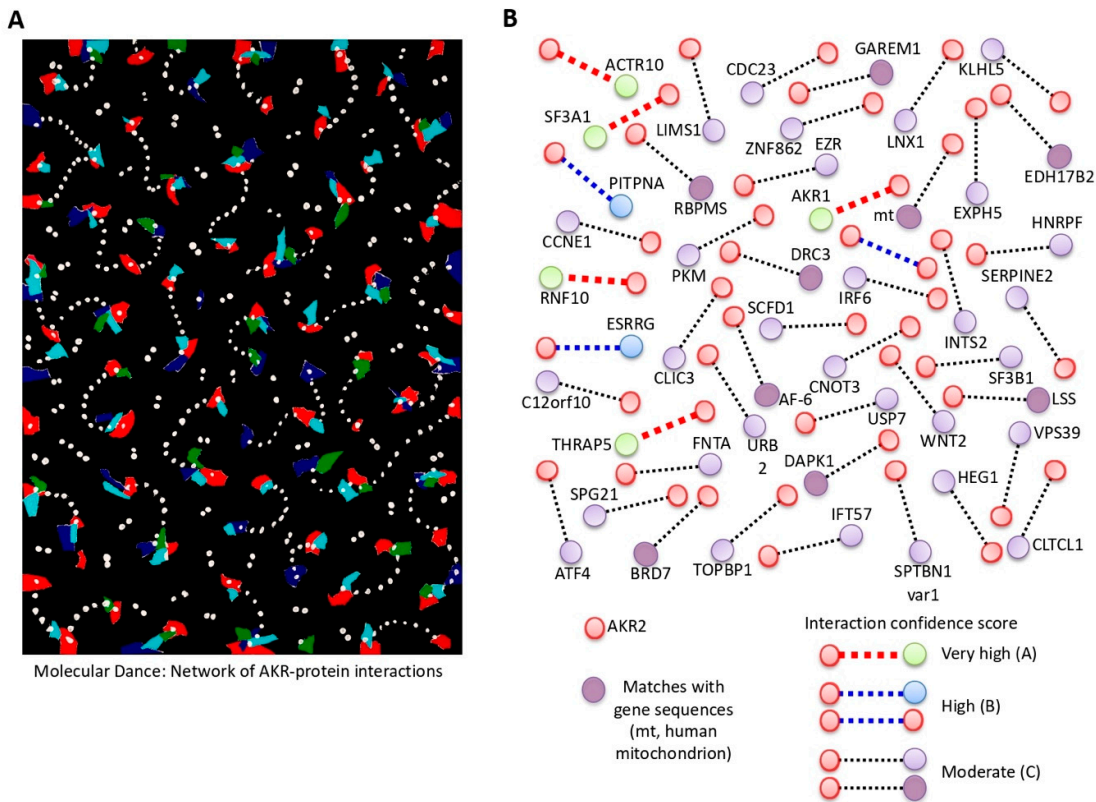

Figure 2. Human AKR2-protein interactions. (A) The piece “La Danza Molecular" (Molecular Dance) by Leandro Soto (mixed media on paper, 2018, $51 \times 71 \mathrm{~cm}$; courtesy KGJ Collection, Spain) also represents protein-protein interactions, and the possibility that AKR/SUB physically interacts with different proteins simultaneously to regulate various biological processes defined by tissue/cell-specific protein-protein interactions. (B) Results of the $\mathrm{Y} 2 \mathrm{H}$ analysis of human AKR2 interactions in human placenta cells. Only proteins identified with A-D scores as potential candidates for interactions with AKR2 are shown. The full description of the proteins is shown in Table 1, Figure S1, and Data S1. 
Table 1. Proteins identified with A-D scores as candidates for interactions with AKR2.

\begin{tabular}{|c|c|c|c|}
\hline Name & Description & Protein/Gene ID & Interaction Score (PBS) \\
\hline AKR1§ & Akirin1 & Q9H9L7 & $\mathrm{A}$ \\
\hline ACTR10 & Actin related protein 10 & Q9NZ32 & A \\
\hline RNF10 $§$ & RING finger protein 10 & Q8N5U6 & A \\
\hline SF3A1 & Splicing factor 3 a subunit 1 & Q15459 & $\mathrm{A}$ \\
\hline THRAP5 $§$ & Mediator of RNA polymerase II transcription subunit 16 & Q9Y2X0 & A \\
\hline AKR2 § & Akirin2 & Q53H80 & $\mathrm{B}$ \\
\hline ESRRG $\S$ & Estrogen related receptor gamma & P62508 & B \\
\hline PITPNA & Phosphatidylinositol transfer protein alpha isoform & Q00169 & B \\
\hline ATF4 & Cyclic AMP-dependent transcription factor ATF-4 & P18848 & $\mathrm{D}$ \\
\hline C12orf10 & Chromosome 12 open reading frame 10 & Q86UA3 & $\mathrm{D}$ \\
\hline CCNE1 & G1/S-specific cyclin-E1 & P24864 & $\mathrm{D}$ \\
\hline $\mathrm{CDC} 23$ & Cell division cycle protein 23 homolog & Q9UJX2 & $\mathrm{D}$ \\
\hline CLIC3 & Chloride intracellular channel protein 3 & O95833 & $\mathrm{D}$ \\
\hline CLTCL1 & Clathrin heavy chain 2 & P53675 & $\mathrm{D}$ \\
\hline CNOT3 & CCR4-NOT transcription complex subunit 3 & O75175 & $\mathrm{D}$ \\
\hline EXPH5 & Exophilin 5 & Q149M6 & $\mathrm{D}$ \\
\hline EZR & Ezrin & P15311 & $\mathrm{D}$ \\
\hline FNTA & Protein farnesyltransferase/geranylgeranyltransferase type-1 subunit alpha & P49354 & $\mathrm{D}$ \\
\hline HEG1 & Protein HEG homolog 1 & Q9ULI3 & $\mathrm{D}$ \\
\hline HNRPF & Heterogeneous nuclear ribonucleoprotein $\mathrm{F}$ & P52597 & $\mathrm{D}$ \\
\hline IFT57 & Intraflagellar transport protein 57 homolog & Q9NWB7 & $\mathrm{D}$ \\
\hline INTS2 & Integrator complex subunit 2 & Q9H0H0 & $\mathrm{D}$ \\
\hline IRF6 $§$ & Interferon regulatory factor 6 & O14896 & $\mathrm{D}$ \\
\hline KLHL5 & Kelch-like 5 isoform 2 variant & Q59HD9 & $\mathrm{D}$ \\
\hline LIMS1 & LIM and senescent cell antigen-like-containing domain protein 1 & P48059 & $\mathrm{D}$ \\
\hline LNX1 & E3 ubiquitin-protein ligase LNX & Q8TBB1 & $\mathrm{D}$ \\
\hline PKM & Pyruvate kinase PKM & P14618 & $\mathrm{D}$ \\
\hline SCFD1 & Sec1 family domain-containing protein 1 & Q8WVM8 & $\mathrm{D}$ \\
\hline SERPINE2 & Glia-derived nexin & P07093 & $\mathrm{D}$ \\
\hline SF3B1 & Splicing factor $3 \mathrm{~B}$ subunit 1 & O75533 & $\mathrm{D}$ \\
\hline SPG21 & Maspardin & Q9NZD8 & $\mathrm{D}$ \\
\hline SPTBN1 var 1 & Spectrin beta chain, non-erythrocytic 1 & Q01082 & $\mathrm{D}$ \\
\hline TOPBP1 & DNA topoisomerase 2-binding protein 1 & Q92547 & $\mathrm{D}$ \\
\hline URB2 & Unhealthy ribosome biogenesis protein 2 homolog & Q14146 & $\mathrm{D}$ \\
\hline
\end{tabular}


Table 1. Cont.

\begin{tabular}{|c|c|c|c|}
\hline Name & Description & Protein/Gene ID & Interaction Score (PBS) \\
\hline USP7 & Ubiquitin carboxyl-terminal hydrolase 7 & Q93009 & $\mathrm{D}$ \\
\hline VPS39 & Vam6/Vps39-like protein & Q996JC1 & $\mathrm{D}$ \\
\hline WNT2 $\S$ & Protein Wnt-2 & P09544 & $\mathrm{D}$ \\
\hline ZNF862 & Zinc finger protein 862 & O60290 & $\mathrm{D}$ \\
\hline GAREM1* & GRB2-associated and regulator of MAPK protein1 & Q9H706 & $\mathrm{D}$ \\
\hline Mitochondrion * & Mitochondrion, complete genome & MF992925 & $\mathrm{D}$ \\
\hline RBPMS * & RNA binding protein, mRNA processing factor (RBPMS), on chromosome 8 & NG_029534.1 & $\mathrm{D}$ \\
\hline BRD7 * & Bromodomain containing 7 (BRD7), on chromosome 16 & NG_023418.1 & $\mathrm{D}$ \\
\hline LSS * & Lanosterol synthase (LSS), on chromosome 21 & NG_011510.1 & $\mathrm{D}$ \\
\hline DRC3 * & DRC3 gene, complete cds & AF282168.1 & $\mathrm{D}$ \\
\hline AF-6 * & AF-6, complete cds & АВ011399.1 & $\mathrm{D}$ \\
\hline DAPK1 * & Death-associated protein kinase 1 (DAPK1) gene, complete cds & DQ436495.1 & $\mathrm{D}$ \\
\hline EDH17B2* & 17-beta-hydroxysteroid dehydrogenase (EDH17B2) gene, complete cds & U34879.1 & $\mathrm{D}$ \\
\hline
\end{tabular}

PBS: A, very high confidence in the interaction; B, high confidence in the interaction; D, moderate confidence in the interaction. ${ }^{\S}$ Proteins previously described as involved in the regulation of the NF-KB signaling pathway. ${ }^{*}$ Entries with gene sequence matches (Data S1). 
In the $\mathrm{Y} 2 \mathrm{H}$ screening used in this study, we did not detect any toxicity, and more than 77 million interactions were tested, which corresponds to a high library coverage (approximately sevenfold the complexity of the library). The results confirmed that the bait was well produced and folded in yeast. A total of 330 prey fragments of the positive clones were amplified by PCR and sequenced at their 5' and 3' junctions (Data S1 and Figure S1). Of them, 47 proteins were identified with A-D scores as candidates for interaction with human AKR2 (Figure $2 \mathrm{~B}$ and Table 1). Focusing on the proteins with very high (A-score) and high (B-score) confidence of interactions, eight interacting proteins were identified (Figure 3A and Table 1). Among the identified prey proteins, AKR1 and AKR2 represented $56 \%$ of the interactions (Figure 3A). The AKR2-interacting proteins were annotated as located in the cytoskeleton, cytoplasm, and nucleus (Figure 3B), suggesting that interactions with AKR2 may occur not only in the nucleus but also in other cell compartments. Functionally, these proteins were annotated as involved in multiple biological processes (Figure 3C). The regulation of transcription by RNA polymerase II, mRNA splicing, and interleukin (IL)-6/IL-12 pathways were the most represented processes, supporting AKR2 role in the regulation of transcription and immune response among other biological processes [17]. To further validate the interaction of these proteins with AKR2 (Figure S1), prediction models illustrated the interacting regions (Figure 3D) and the percent of residue-residue interactions for selected identified proteins but not for the human interferon alpha 1 (IFN- $\alpha 1$ ) used as negative control (Figure 3E).

A

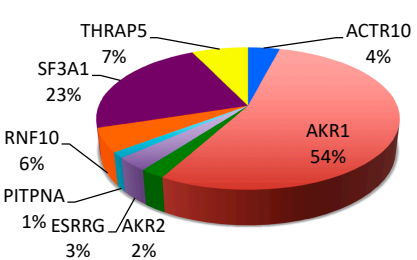

$3 \% \quad 2 \%$

D

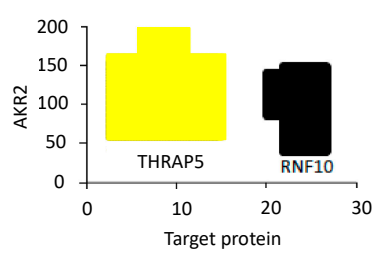

E
B
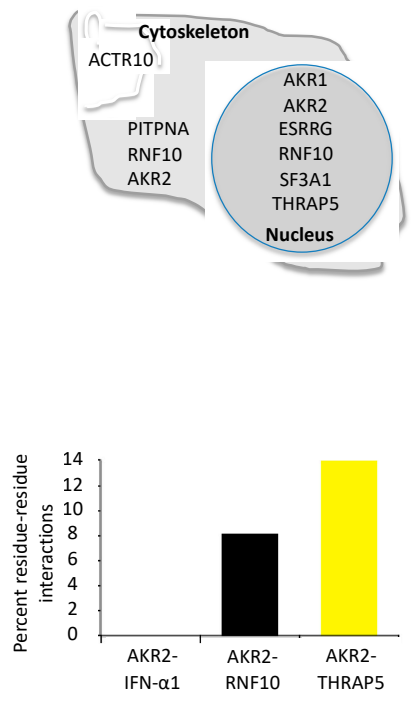

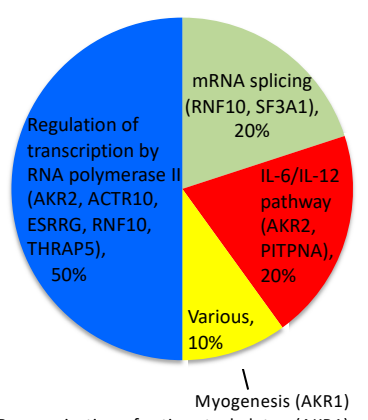

Reorganization of actin cytoskeleton (AKR1) PI3 kinase dependent pathway (AKR1) Embryo development (AKR2) immune response (AKR2)
Cell proliferation (AKR2) Response to lipopolysaccharide (AKR2) Antigen presentation via MHC II (ACTR10) Microtubule-based movement (ACTR10) Neutrophil degranulation (ACTR10) Cold-induced thermogenesis (ESRRG) Axonogenesis (PITPNA) ipid metabolic process (PITPNA) Visual perception (PITPNA) Protein autoubiquitination (RFN10) Myelination Schwann cell proliferation

(RFN10)
ER to Golgi vesicle-mediated transport (ACTR10)
Androgen/steroid hormone receptor signaling pathway (RFN10)

Figure 3. Characterization of human AKR2-protein interactions with highest confidence. (A) Representation of the percentage of total interactions after $\mathrm{Y} 2 \mathrm{H}$ by proteins with very high and high confidence of interactions with human AKR2 in human placenta cells. (B) Subcellular localization of AKR2-interacting proteins. (C) Biological processes associated with AKR2-interacting proteins. (D) Prediction of specific interacting residues of human AKR2 with THRAP5 (Q9Y2X0) and RNF10 (Q8N5U6) proteins. The interacting residues formed by AKR2 dimer (amino acids 59-159) are not shown. (E) Predicted model of the percentage of amino acids involved in residue-residue interactions for human AKR2-interferon alpha 1 (IFN-a1) (negative control), AKR2-RNF10, and AKR2-THRAP5. Predictions in (D,E) were made using the iFrag server (http://sbi.imim.es/web/index.php/research/servers/iFrag?), and protein structure models were obtained from The Protein Model Portal.

Finally, AKR2-protein interactions were confirmed in vitro with recombinant proteins for identified prey and including the SNRNP70 protein with score F (experimentally proven technical artifact) as 
negative control (Figure 4A-D). A protein pull-down approach was used with c-Myc magnetic beads specific for the AKR2 protein tag and followed by immunoprecipitation of AKR2-interacting recombinant proteins with antibodies specific for the interacting proteins (Figure 4A). The results showed that all AKR2-interacting protein bands were identified in the interaction (I) and with a similar size to the positive control $(\mathrm{C}+)$, except for the interactions with the c-Myc magnetic beads only (C-) and the non-interacting SNRNP70 negative control (Figure 4B,C). However, other protein bands were observed in both (I) and (C-) lanes at lower molecular weight than the AKR2-interacting proteins (Figure 4B,C). In order to identify these unrelated proteins eluted from the c-Myc magnetic beads, a similar experiment was conducted with selected proteins but incubating only with the secondary antibody. The results suggested that these bands corresponded to fragments of the mouse anti-c-Myc antibody attached to magnetic beads, which was further supported by the fact that these bands were more evident when using mouse-derived anti-interacting protein antibodies and the mouse secondary antibody with higher reactivity to the mouse anti-c-Myc antibody attached to magnetic beads (Figure 4A,D). Finally, this experimental approach provided additional support for AKR2-AKR2 interactions by identifying not only the AKR2 monomer, but also protein dimer and trimer (Figure 4C).
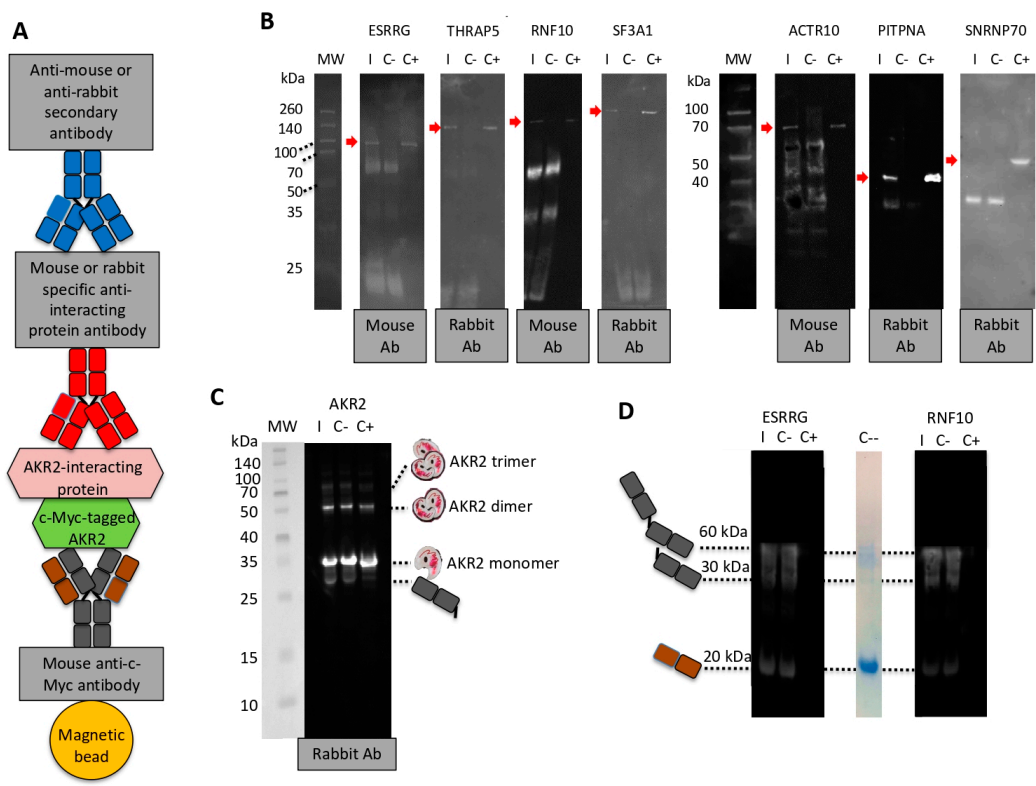

Figure 4. Corroboration of human AKR2-protein interactions with highest confidence. (A) Representation of the components of the protein pull-down experiment using c-Myc magnetic beads with Myc-tagged human AKR2. (B) Western blot analysis of AKR2-protein interactions. Interacting proteins were incubated with AKR2 and immunopresipitated with c-Myc magnetic beads specific for the AKR2 protein tag (I) or with the c-Myc magnetic beads only as negative control (C-). Recombinant interacting proteins were included as positive control $(\mathrm{C}+)$. Mouse or rabbit antibodies specific for each protein were used as primary antibodies and then anti-mouse or anti-rabbit secondary antibodies were used to identify the presence of the interacting proteins (red arrow). The origin of the primary antibody is shown. (C) Corroboration of human AKR2-AKR2 interaction using protein pull-down with c-Myc magnetic beads with human Myc-tagged AKR2. The experiment was conducted as described in (B). The origin of the primary antibody and predicted size for AKR2 monomer, dimer, and trimer together with bands corresponding to fragments of the mouse anti-c-Myc antibody attached to magnetic beads are shown. (D) In order to identify unrelated proteins eluted from the c-Myc magnetic beads, a similar experiment was conducted with selected proteins but incubating only with the secondary antibody. A lane of SDS-PAGE stained with Bio-Safe Coomassie Stain corresponding to c-Myc magnetic beads alone eluted using Laemmli sample buffer was included $(\mathrm{C}-)$. The bands corresponding to fragments of the mouse anti-c-Myc antibody attached to magnetic beads are shown. 
Twenty-four AKR2-protein physical interactions have been described before in human kidney, colon, lung, and mammary epithelial cells [19-23]. Of them, only three proteins were among the identified proteins in human placenta with very high (A; AKR1) or moderate (D; maspardin (SPG21) and E3 ubiquitin-protein ligase LNX (LNX1)) interaction scores (Figure 2B, Table 1, and Data S1). In STRING and NCBI databases of AKR2-protein interactions using Y2H and other alternative interactome models such as IPA, the interactions of AKR2 with AKR1, RNF10, zinc finger protein 862 (ZNF862), LNX1, and SPG21 were identified.

\subsection{The Sound of the AKR/SUB Coding Sequence Supported Evolutionary Conservation and Functional Protein Interactions}

Previously, we proposed an algorithm to characterize genome structural features on the basis of the fact that the non-random organization of the genome must have left a structural imprinting in the sound of the DNA language [8]. This method was based on the communicative strength of music to show the presence of syntactical structures in the DNA language, and some properties of these structures [8]. Herein, we applied an improved version of this method to translate AKR/SUB sequences into musical scores and music (Figures S2 and S3) to provide an alternative and complementary approach to the study of AKR evolutionary relationships and functional protein interactions. As shown previously by genetic approaches [17], musical ensembles supported the fact that AKR in different species are evolutionarily related and structurally conserved (Figure 5A,B and Figure S3). The results showed characteristics of the AKR/SUB proteins evidenced by the predominance of certain melodic formulas in each species, the fact that a single melodic form was never repeated more than three consecutive times, and that all species showed spaces with lower rhythmic movement (Figure 5A). When comparing the AKR/SUB from the six analyzed species (Figure 5A) in a polyphonic context, the results showed the presence of unisons, long sequences of unisons, and melodic imitation effects even having long canonical structures that represent regions of amino acid homology between species (Figure 5B). To use this approach to further characterize the AKR/SUB interactome, the sequences of AKR2-interacting proteins RNF10 and THRAP5 (Table 1) and IFN- $\alpha 1$ as negative control were translated into music (Figure S2) to produce musical ensembles of AKR2-protein interactions by trial and error. The results showed that both AKR2-RNF10 and AKR2-THRAP5 but not AKR2-IFN- $\alpha 1$ musical ensembles (Figure S4) predicted protein interactions coinciding with those found by $\mathrm{Y} 2 \mathrm{H}$ (Figure $5 \mathrm{C}$ ).

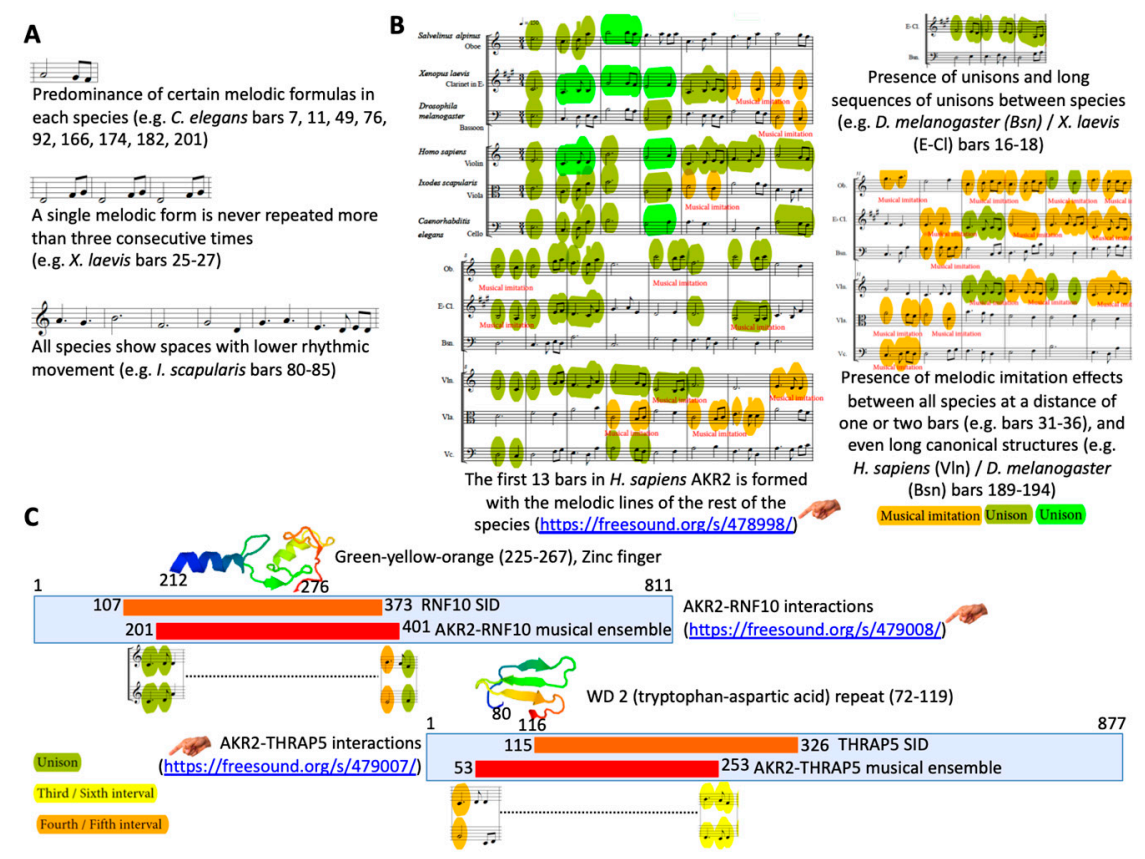

Figure 5. The sound of AKR evolution and protein interactions. (A) Examples of regularities observed 
when comparing AKR/SUB musical scores between different species (Caenorhabditis elegans akr NM_058903.6, Drosophila melanogaster akr NM_139856.4, I. scapularis akr/subolesin AY652654.1, Xenopus laevis akr2 NM_001092015.1, Salvelinus alpinus akr2 GQ247760.1, and Homo sapiens akr2 NM_018064.3; Figure S2). (B) Examples of the findings when comparing the six species in a polyphonic context (Figure S3). (C) The AKR2-RNF10 and AKR2-THRAP5 but not AKR2-IFN- $\alpha 1$ interactions are manifested in the higher and repeated presence of unison between both sequences (e.g., AKR2-RNF10 bars 232-235, AKR2-THRAP5 bars 83-85), as well as a higher presence of fifth and fourth consonances (e.g., AKR2-RNF10 bars 210-219, AKR2-THRAP5 bars 67-78) (Figure S4). Audio files were uploaded and can be found in Figure S4 (78998 to 479009).

\subsection{AKR2-Protein Interactions Positively and Negatively Regulated the NF- $\kappa B$ Signaling Pathway}

The next step in the characterization of AKR2-protein interactions was to address the question of how these interactions functionally regulate specific signaling pathways. In the piece "Nothing wants to say something" (Figure 6A), the artist proposed a new approach to address scientific challenges on the basis of "visual vibrations" that somehow should modify the experience and internal chemical processes that occur when looking at a piece of art. According to the artist's statement, "what you are looking for is also looking for you, highlighting that nothing wants to tell you something and it is only a matter of finding how to perceive the message". From a scientist's perspective, this message challenges the view that AKR/SUB-protein interactions occur randomly, and suggests that these interactions are functionally relevant in the regulation of different biological processes as occurs with other regulatory factors [44]. To address this question, the NF- $\kappa$ B signaling pathway was selected due to its role in the IMD immune response biological process [15-17,26,28]. We first identified proteins previously described as implicated in the regulation of the evolutionarily conserved NF- $\mathrm{B}$ pathway (Table 1) [45-51]. Then, the interactions between AKR2-IRF6 and AKR2-WNT2 (D-score moderate confidence of interactions; Table 1) was corroborated in vitro (Figure 6B). The characterization of the AKR2-interacting unrelated proteins with lower molecular weight was addressed before (Figure 4A,D). The genes coding for these proteins were knockdown (Figure 6C and Figure S5) or protein levels increased by protein transfection (Figure 6D) in human placenta cells alone and in combination with AKR2 to characterize their role in the regulation of the NF- $\mathrm{BB}$ signaling pathway.

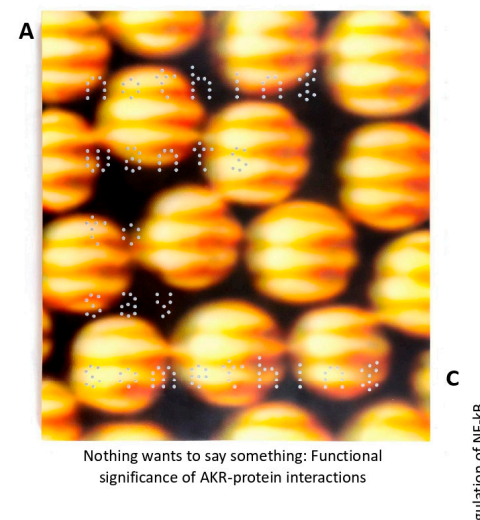

D

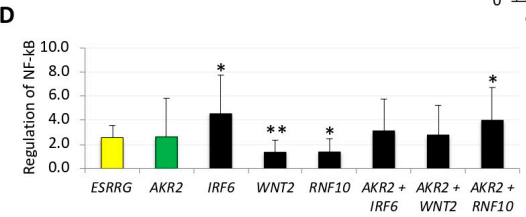

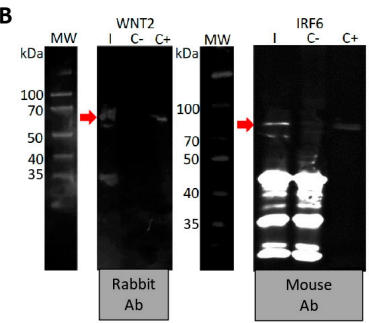

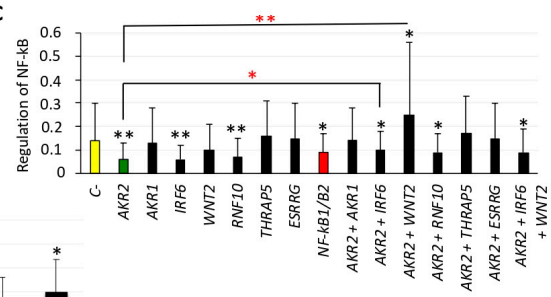

Figure 6. Function of AKR2 interactome in the regulation of NF-кB. (A) The piece "Nothing wants to say something" by Raúl Cordero (acrylic, polyester, oil and metallic pigments on canvas, $210 \times 190 \mathrm{~cm}$; 
courtesy of the artist) challenges the view of random AKR-protein interactions and suggests that these interactions are functionally relevant in the regulation of different biological processes. (B) Western blot analysis of AKR2-IRF6 and AKR2-WNT2 interactions. Interacting proteins were incubated with AKR2 and immunoprecipitated with c-Myc magnetic beads specific for the AKR2 protein tag (I) or with the c-Myc magnetic beads only as negative control (C-). Recombinant interacting proteins were included as positive control $(\mathrm{C}+)$. Antibodies specific for each protein were used to identify the presence of the interacting proteins (red arrow). The origin of the primary antibody is shown. (C,D) Regulation of NF- $\mathrm{kB}$ in response to AKR2 and interacting proteins. (C) The NF- $\mathrm{kB}$ reporter was used for monitoring the activity of the NF- $\mathrm{kB}$ signaling pathway in human placenta-cultured cells after gene knockdown by RNAi. The ratio of firefly luminescence from the NF- $\mathrm{kB}$ reporter to Renilla luciferase vector control was represented as average $+\mathrm{SD}$ and compared between siRNA-treated groups and the siRNA negative control (C-) (black asterisks), and between combined siRNA-treated groups and the AKR2 siRNA (red asterisks) by Student's $t$-test with unequal variance and one-way ANOVA with similar results $\left({ }^{*} p<0.05\right.$, ** $p<0.005 ; n=6$ biological replicates). (D) The NF-kB reporter was used for monitoring the activity of the NF- $\mathrm{KB}$ signaling pathway in human placenta cells after transfection of recombinant proteins AKR2, RNF10, WNT2, IRF6, and combinations with AKR2. As a positive control, a FITC-antibody was transfected. Negative control cells were transfected with the ESRRG protein. The firefly to Renilla normalized luciferase activity for NF- $\mathrm{kB}$ reporter was represented as average + SD and compared between protein-treated groups and the ESRRG control by Student's $t$-test with unequal variance $\left({ }^{*} p<0.05,{ }^{* *} p<0.005 ; n=4\right.$ biological replicates).

The results of gene knockdown experiments provided evidence for the role of AKR2, IRF6, RNF10, and AKR2 interactions with IRF6, RNF10, and IRF6/WNT2 in the positive regulation of NF- $K B$, whereas AKR2-WNT2 interactions appeared to negatively regulate the NF- $\mathrm{B}$ signaling pathway (Figure 6C). ESRRG alone or in combination with AKR2 did not affect NF-kB regulation (Figure 6C) and was used as a negative control in the protein transfection experiment (Figure 6D). The increase in protein levels corroborated the NF- $\mathrm{KB}$ positive regulation by IRF6 and AKR2-RNF10 interactions, whereas transfection of WNT2 and RNF10 proteins resulted in the negative regulation of NF- $\mathrm{B}$ (Figure 6D). Transfection of AKR2 alone did not affect NF- $k B$ regulation (Figure 6D). Discrepancies between results of gene knockdown (Figure 6C) and protein transfection (Figure 6D) experiments may be explained at least in part by the fact that proteins appeared to directly enter cell nucleus after transfection (Figure 7A), which may prevent post-translational modifications required for protein function. In this case, post-translational modifications would have functional implications for AKR2 and RNF10. Additionally, differences between results of $A K R 2$ gene knockdown and protein transfection may also suggest that AKR2 is necessary but not sufficient to upregulate NF- $\kappa B$ (Figure $6 C, D)$.

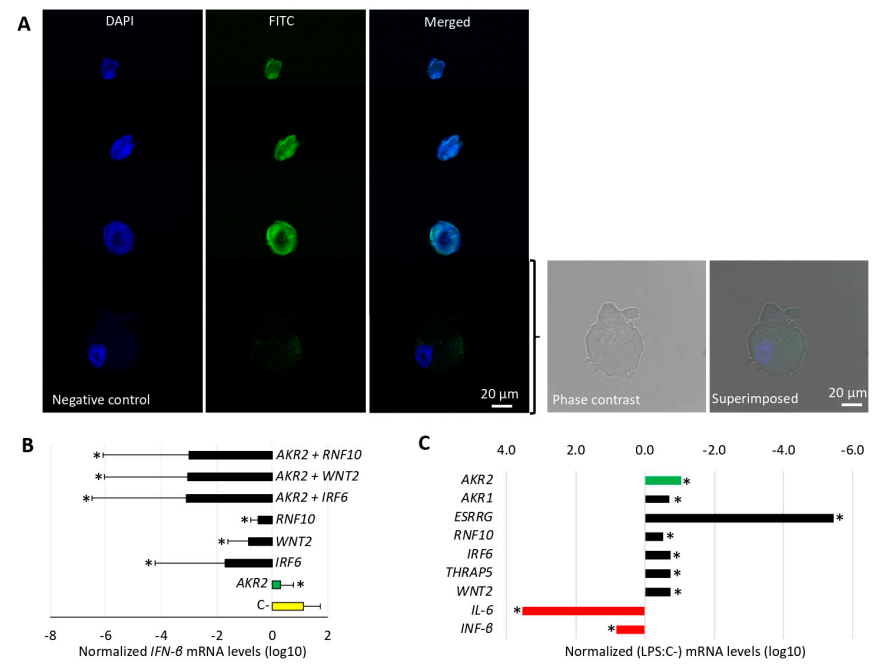

Figure 7. AKR2 interactome differentially regulated the NF-kB pathway. (A) Protein transfection 
was confirmed in FITC-antibody positive control-transfected cells and untreated negative control cells by fluorescence microscopy. Host cell nucleus was stained with DAPI (blue). Image of negative control cells was also collected by phase contrast microscopy and superimposed to FITC/DAPI merged image. Bar: $20 \mu \mathrm{m}$. (B) The expression of IFN- $\beta$ was characterized in human placenta cells after gene knockdown by qRT-PCR. The IFN- $\beta$ mRNA levels were normalized against human $\beta$-actin, and normalized $\mathrm{Ct}$ values were compared between test siRNA-treated placenta cells and controls treated with non-targeting siRNA (C-) by Student's $t$-test with unequal variance ${ }^{*} p<0.05 ; n=6$ biological replicates). (C) The expression of AKR2; genes coding for interacting proteins AKR1, ESRRG, RNF10, THRAP5, IRF6, and WNT2; and regulated genes IFN- $\beta$ and $I L-6$ was characterized in human placenta cells treated with lipopolysaccharides (LPS) by qRT-PCR. The mRNA levels were normalized against human $\beta$-actin, the normalized LPS to PBS-treated control (C-) ratio (LPS: C-) Ct values were calculated, and normalized $\mathrm{Ct}$ values were compared between LPS-treated and C-cells by chi $^{2}$ test ${ }^{*} p<0.001$; $n=6$ biological replicates).

The expression of IFN- $\beta$ gene regulated by IRF and NF- $\mathrm{BB}$ factors [52-56] and therefore identified as an NF-kB target gene (https://www.bu.edu/NF-\$ $\backslash$ upkappa\$B/gene-resources/target-genes/) was characterized in human placenta cells after gene knockdown (Figure 7B). The knockdown of $A K R 2$, IRF6, WNT2, and RNF10 alone and in combination with $A K R 2$ resulted in significant downregulation of IFN- $\beta$ (Figure 7B). This effect was higher for combined AKR2-RNF10, AKR2-WNT2, and AKR2-IRF6 gene knockdown with a downregulation of $I F N-\beta$ by 13,400- to 16,750-fold (Figure 7B).

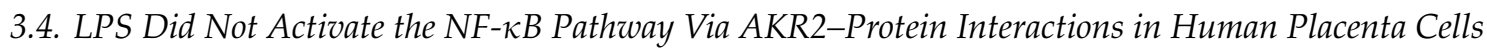

Bacterial LPS binding to Toll-like receptor 4 (TLR4) results in the activation and translocation of NF- $\kappa \mathrm{B}$ transcription factor into the nucleus, which activates the expression of target genes such as $I L-6, I L-8, I F N-\beta$, and tumor necrosis factor (TNF) $[57,58]$ that have been implicated in the response to LPS in placenta cells [59]. However, LPS-mediated TLR4 signaling occurs through the myeloid differentiation primary response gene 88 (MyD88) and signaling adaptor protein TIR domain-containing adaptor-inducing interferon-beta (TRIF), which regulate NF- $k B$ translocation into the nucleus to induce gene transcription [60].

To explore the possible role of AKR2 and the interacting proteins in the NF- $\mathrm{KB}$ signaling pathway in response to LPS, human placenta cells were treated with LPS and the expression of selected genes characterized by qRT-PCR (Figure 7C and Figure S6). The results showed that LPS treatment induced downregulation of genes coding for AKR2 and the interacting proteins AKR1, ESRRG, RNF10, IRF6, THRAP5, and WNT2 (Figure 7C). However, the NF-kB-regulated genes IL-6 and IFN- $\beta$ were induced in LPS-treated placenta cells, thus supporting NF- $\mathrm{B}$ activation in response to LPS (Figure 7C). These results supported the fact that AKR2-protein interactions do not mediate LPS activation of the NF- $\mathrm{KB}$ pathway in human placenta cells. In these cells, alternative mechanisms such as those mediated by MyD88 and TRIF or others still to be characterized may be involved in the activation of the NF- $\kappa B$ signaling pathway. Nevertheless, LPS-induced down regulation of AKR2 interacting proteins with negative regulation of NF-kB may be a compensatory mechanism to favor the production of certain NF-kB regulated genes such as IFN- $\beta$. The downregulation of genes coding for AKR2 and interacting proteins in response to LPS may constitute a mechanism by which placenta cells alter NF- $\mathrm{B}$ dynamics.

\subsection{The Characterization of the AKR/SUB Interactome Had Implications for Quantum Vaccinomics}

The proposed pipeline for quantum vaccinomics consisted of the following steps (Figure 8A): (a) characterization of cell interactome and regulome in vector-host-pathogen interactions for the identification of proteins such as AKR/SUB involved in the regulation of multiple biological processes through physical interactions with other proteins; (b) identification, modeling, and characterization of protein SID; (c) prediction and characterization of conserved protective epitopes in protein SID; and (d) design and production of chimeric protective antigens. 
A

Identification of proteins involved in the regulation of multiple biological processes through physical interactions with other proteins

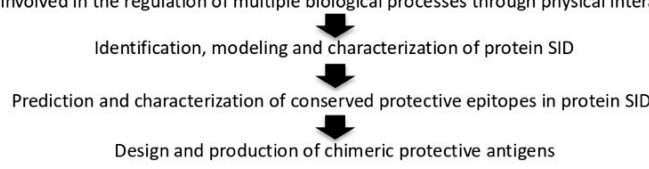

B

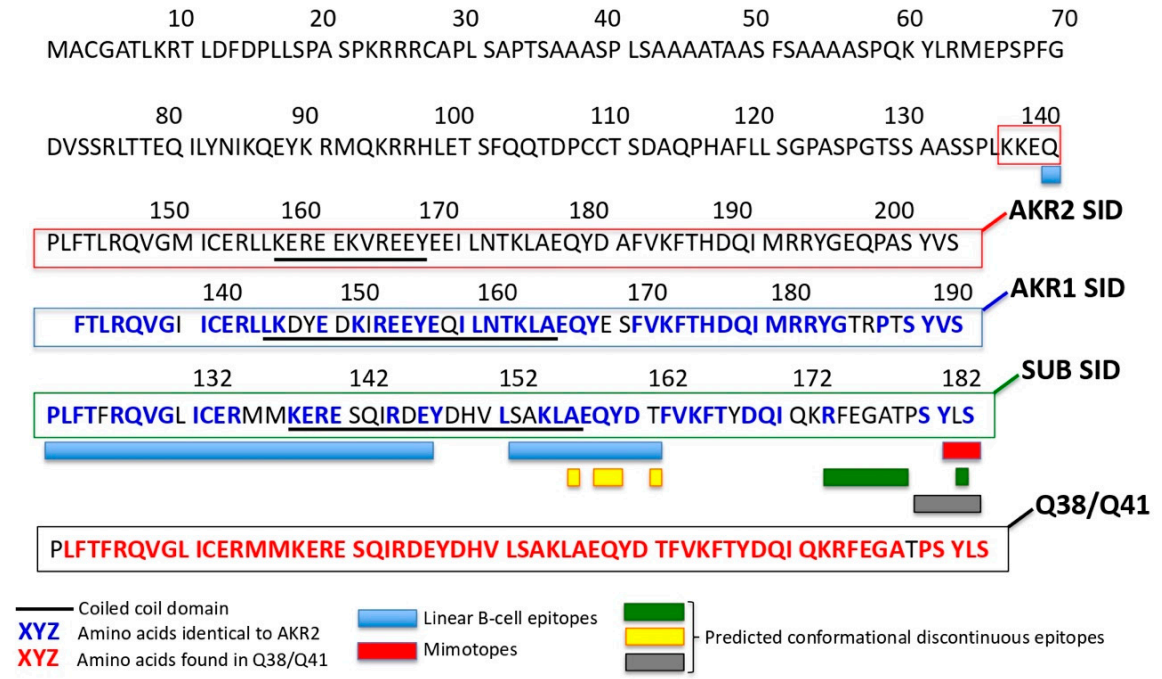

Figure 8. SUB/AKR interactome and possibilities for quantum vaccinomics. (A) Pipeline for quantum vaccinomics by focusing on protective epitopes in peptide sequences involved in protein-protein interactions or SID that are particularly relevant for proteins such as SUB/AKR that function through these interactions. (B) Alignment of SID amino acid sequences for human AKR2 and AKR1, and I. scapularis tick SUB with the corresponding region in the SUB/AKR chimeric Q38 and Q41 protective antigens. The Q38- and Q41-identified and/or predicted protective epitopes are shown.

As a proof-of-concept, the SID identified here in AKR2 and AKR1, and predicted for tick SUB [17] were aligned and showed more than $60 \%$ amino acid sequence identity (Figure $8 \mathrm{~B}$ ). Then, the protective epitopes included into Q38 and Q41 AKR/SUB chimeras [34,38] were mapped and covered more than $75 \%$ of the SID (Figure 9B). Considering the protective efficacy of Q38 and Q41-based vaccines [34,35,61], these results supported targeting SID in quantum vaccinomics.

A
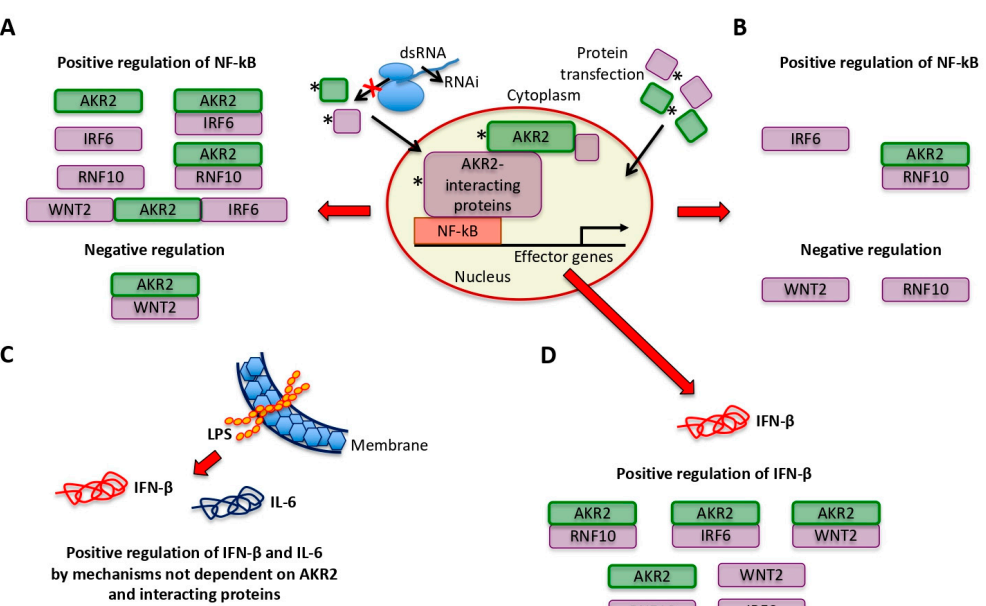

Positive regulation of IFN- $\beta$

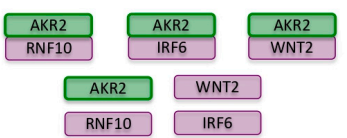

Figure 9. Model for NF- $\kappa B$ regulation by human AKR2 interactome in human placenta cells after (A) gene knockdown by RNAi, (B) protein transfection, (C) IFN- $\beta$ and IL-6 expression after treatment with LPS, and (D) IFN- $\beta$ expression after gene knockdown by RNAi. Predictions are based on results from experiments shown in Figure 6C,D and Figure 7B,C. 


\section{Discussions}

Our combined scientific and artistic perspectives provided a multidisciplinary complementary approach to advance the knowledge of the AKR/SUB model regulatory factor and supported the collaboration between science and art in research (Table 2). It has been proposed that AKR/SUB acts through functional interactions with other proteins and chromatin remodeling [16,17,19-28], but additional information is needed about the role of AKR/SUB interactome in these processes. Artists did not merely illustrate scientific results but provided their perspectives on the AKR/SUB-protein interactions, which challenged scientists to provide mechanistic and regulatory insights into the functional implications of these interactions.

Table 2. Highlights of the collaboration between artists and scientists in this study.

\begin{tabular}{ll}
\hline \multicolumn{1}{c}{ Artist Contribution } & \multicolumn{1}{c}{ Scientist Perspective } \\
\hline \multicolumn{1}{c}{ Methodological Approach } \\
$\begin{array}{ll}\text { Three visual artists and a musician were invited to } \\
\text { read a simplified version of our recent review on }\end{array}$ & $\begin{array}{l}\text { In response to this challenge, the artists contributed } \\
\text { the pieces, musical scores, and interpretations shown } \\
\text { AKR/SUB functional evolution [17] and were } \\
\text { challenged with the conserved function of these } \\
\text { proteins in the regulation of different biological } \\
\text { processes throughout the metazoan. }\end{array}$ \\
$\begin{array}{l}\text { matter. Artists' contributions served to inspire } \\
\text { scientists to discuss and find new perspectives on } \\
\text { unexplored characteristics of these proteins with }\end{array}$ \\
\hline
\end{tabular}

Piece in Figure $1 \mathrm{~A}$

The artist represents the origins of life, with multiple geometric images that interact to illustrate in different species the conserved function of these proteins in biological processes represented by the sea, paper boat, Picasso's dove, and a fetus growing in a mother's womb while opening its eyes to the world.

From a scientist's perspective, a new and unexplored facet of possible functional relevance of AKR dimerization was proposed in this piece.

\begin{tabular}{ll}
\hline \multicolumn{1}{c}{ Piece in Figure 2A } \\
$\begin{array}{l}\text { The artist describes the constant movement of these } \\
\text { proteins that translate into the visual rhythm of } \\
\text { repetitive interconnected interactions of forms and } \\
\text { colors. }\end{array}$ & $\begin{array}{l}\text { From a scientist's perspective, the possibility that } \\
\text { AKR physically interacts with different proteins } \\
\text { simultaneously to regulate various biological } \\
\text { processes defined by cell-specific AKR-protein } \\
\text { interactions was proposed in this piece. }\end{array}$ \\
\hline \multicolumn{1}{c}{ Piece in Figure 6A }
\end{tabular}

Phylogenetic or evolutionary trees are the most accepted approach to illustrate the inferred evolutionary relationships between different species on the basis of the similarities and differences in their physical or genetic characteristics. Furthermore, selective evolutionary pressures have driven a non-simple random-based organization of the genome of surviving organisms. Several methods have 
been applied to the formulation of DNA language and encoded information, showing that there is at least some degree of organization in the nucleotide sequences found in many organisms [8,62-64]. Our results advanced the use of the DNA language approach a step forward by characterizing not only evolutionary relationships but also functional protein interactions (Table 2).

The results supported the fact that the multiple interactions between AKR2 and interacting proteins differentially regulate the NF- $\mathrm{KB}$ pathway by affecting gene expression controlled by NF- $\mathrm{KB}$ in a biological context-dependent manner (Figure 8A-D). In all experiments, except in LPS-treated cells, the results suggested that AKR2 and IRF6 alone and the combination of AKR2-RNF10 positively regulate the NF- $\kappa B$ signaling pathway. Differences between different experiments support the possibility of the differential regulation of the NF- $\mathrm{KB}$ pathway in a biological context-dependent manner.

Of the identified AKR2-protein interactions in human placenta cells, five proteins with very high confidence in the interactions representing $9.6 \%$ of the identified proteins included AKR1, ACTR10, RNF10, SF3A1, and THRAP5 (Table 1). Of them, AKR1, RNF10, and THRAP5 have been previously described as involved in the regulation of the NF- $\mathrm{KB}$ signaling pathway [45-51]. One of the remaining challenges addressed in this study by using the NF- $\mathrm{kB}$ signaling pathway as a model was the characterization of the mechanisms by which AKR2-protein interactions are regulated by cell type-specific models that in turn regulate different biological processes (i.e., immune response or development). It has been proposed that AKR/SUB specifies NF-kB selectivity of innate immune response via chromatin remodeling $[25,27]$. However, the results of our study provided evidence suggesting that in human placenta cells the differential interaction between AKR2 and the interacting proteins IRF6, RNF10, and WNT2 differentially regulate the NF- $\mathrm{B}$ signaling pathway. The role of AKR dimerization/multimerization in the regulation of these protein interactions is also potentially functionally relevant and requires additional research.

Previously, van Essen et al. [38] proposed that the activation of NF- $\kappa$ B by NF- $\kappa B$ (p65) depends on the availability of suitable secondary transcription factors, a process determined by cell-type and stimulus. Herein, we showed that some of these secondary transcription factors may be AKR2 and interacting proteins, and suggested that AKR2-protein interactions may affect gene expression controlled by NF- $\mathrm{KB}$ in a biological context-dependent manner. The fact that $A K R 2$ gene knockdown but not protein transfection affected NF- $\mathrm{KB}$ regulation provided additional evidence that AKR2 needs to interact with other proteins to activate the NF- $\mathrm{kB}$ pathway [28]. Additionally, the results supported the role proposed previously for post-translational modifications in the function of AKR/SUB and interacting proteins $[17,24]$.

Quantum vaccinomics will advance the design of more effective and safe vaccines to target some of the challenges posed for ectoparasite control vaccines [65]. The algorithm for quantum vaccinomics proposed here focusses on proteins involved in cell interactome and regulome and functioning through protein-protein interactions for the regulation of multiple biological processes involved in vector-host-pathogen interactions. In this way, vaccination with AKR/SUB protective epitopes in SID will induce an antibody response not only interfering with protein translocation to the nucleus [66], but also blocking AKR/SUB-protein interactions involved in the regulation of multiple biological processes. Vaccines based on Q38 and Q41 AKR/SUB protective epitopes chimeras have proven efficacy for the control of different ectoparasites and infection by vector-borne pathogens [34,35,61]. Nevertheless, future experiments should address the effect of these vaccines on the regulation of various biological processes to further advance the possibility of developing a vaccine for the control of vector infestations and pathogen infection/transmission by multiple species [67].

\section{Conclusions}

The results of this study provided a novel combined scientific and artistic multidisciplinary approach to address challenging questions in molecular biology. The collaboration between scientists and artists provided two main methodological outcomes: (a) the suggestion by visual artists of the scientific characterization of previously unexplored properties of AKR/SUB and (b) the application 
of an algorithm using musical ensembles based on AKR/SUB and interacting protein sequences as a new method to predict protein-protein interactions (Table 2). The recent review of AKR/SUB functional evolution [17] suggested that these proteins evolved with conserved sequence, structure, and function, and that there is a need to further characterize its function in different conserved biological pathways such as NF-KB. The need to better understand AKR/SUB function was addressed in this study, and although further experiments are required to fully characterize the role of the AKR/SUB interactome in the regulation of the NF- $\mathrm{KB}$ pathway, the results in human placenta cells served as a methodological proof-of-concept to advance this research area. The results showed that AKR-AKR interactions result in protein dimerization/multimerization with possible functional implications that require attention. AKR/SUB physically interacts with different proteins simultaneously to regulate various biological processes with cell type differences in AKR2 interactome that are likely associated with the specific biological processes regulated by this protein in each cell type. In this way, multiple interactions between AKR2 and interacting proteins differentially regulate the NF- $\mathrm{B}$ pathway by affecting gene expression controlled by NF- $\mathrm{KB}$ in a biological context-dependent manner. In addition to cell type-specific differences in AKR/SUB-protein interactions, species-specific differences have been also described and require further attention [17]. For example, it has been shown in tick cells that SUB regulome affects multiple biological processes that vary in response to infection with the tick-borne pathogen Anaplasma phagocytophilum [17]. Therefore, studies in other cells such as lymphocytes or monocytes and promyelocytic leukemia HL-60 model cells are required to evaluate cell type-specific differences in the function of AKR2-protein interactions in NF- $\kappa$ B signaling. Functionally, AKR2-protein interactions in human placenta cells differentially regulate the NF- $\mathrm{B}$ signaling pathway, suggesting that AKR2 interacting proteins might constitute suitable secondary transcription factors for cell and stimulus-specific regulation of NF-кB. As shown previously by genetic approaches, musical ensembles supported the fact that AKR/SUB in different species are evolutionarily related and structurally conserved, and also predicted AKR2-protein interactions coinciding with those found by genetic approaches such as the $\mathrm{Y} 2 \mathrm{H}$ screening used here. The methodological approach proposed here for quantum vaccinomics further advances the potential of the vaccinomics pipeline used before for the identification of candidate protective antigens [29,68,69]. Furthermore, if combined with network analysis for the integration of interactomics and regulomics datasets [70] and big data machine learning algorithms to identify candidate protective antigens and epitopes [71], quantum vaccinomics would result in designing chimeric antigens based on protective epitopes in SID from vector- and pathogen-derived regulatory proteins. Vaccines with these chimeric protective antigens would address the possibility of effective and sustainable control of vector-borne diseases by targeting multiple ectoparasite and pathogen species in multiple hosts. The collaboration between scientists and artists from multiple disciplines has a positive impact on advancing research to address scientific challenges.

Supplementary Materials: The following are available online at http://www.mdpi.com/2076-393X/8/1/77/s1: Figure S1: Annotation of the AKR2-protein interacting domains. Figure S2: Translation of AKR and selected interacting protein sequences into musical scores. Figure S3: Multi-species AKR musical ensemble. Figure S4: Musical ensemble of AKR2-protein interactions. Figure S5: Gene knockdown by RNAi in human placenta cells. Figure S6: Gene expression in LPS-treated human placenta cells and controls. Data S1: Results of the ULTImate Y2H screening of human AKR2 bait vs. human placenta RP6 library prey.

Author Contributions: J.d.l.F. conceived the study and publication. J.J.P.C. provided musical perspective and analyses. I.L.V., L.S., and R.C. provided visual artists perspectives. S.A-J., M.V., P.A., and M.C. performed the experiments. J.J.V. conducted predictive model analysis of protein-protein interactions. J.d.l.F., S.A-J., A.C.-C., and A.E.-P. interacted with the artists' perspectives. J.d.I.F., S.A.-J., and J.J.P.C. wrote the manuscript. All authors have read and agreed to the published version of the manuscript.

Funding: This work was financially supported by the Ministerio de Economía, Industria y Competitividad (Spain) grant BFU2016-79892-P. M.V. was funded by the University of Castilla La Mancha, Spain.

Acknowledgments: We would like to thank Ernesto Doncel Pérez (Neuroregenerative Chemistry Department) and Rodrigo Maza, Manuel Nieto, and Teresa Muñoz de Galdeano (Molecular Neuroprotection Department) from National Hospital of Paraplegics, Toledo, Spain, for technical assistance.

Conflicts of Interest: The authors declare no conflict of interest. 


\section{References}

1. Jeffries, S. When two tribes meet: Collaborations between artists and scientists. The Guardian. 21 August 2011. Available online: https://www.theguardian.com/artanddesign/2011/aug/21/collaborations-betweenartists-and-scientists (accessed on 1 August 2019).

2. Tayag, Y.; Wells, B. Art and evolution: A work in progress. Scientific American. 6 May 2014. Available online: https://blogs.scientificamerican.com/guest-blog/art-and-evolution-a-work-in-progress/ (accessed on 1 August 2019).

3. Schulkin, J.; Raglan, G.B. The evolution of music and human social capability. Front. Neurosci. 2014, 8, 292. [CrossRef] [PubMed]

4. de la Fuente, J.; Estrada-Peña, A.; Cabezas-Cruz, A.; Brey, R. Flying ticks: Anciently evolved associations that constitute a risk of infectious disease spread. Parasit. Vectors 2015, 8, 538. [CrossRef] [PubMed]

5. Veis, N. Four takes in the evolution of art. Nature 2017, 543, 490. [CrossRef]

6. Stevens, C.; O'Connor, G. When artists get involved in research, science benefits. The Conversation. 16 August 2017. Available online: http://theconversation.com/when-artists-get-involved-in-research-science-benefits82147 (accessed on 1 August 2019).

7. de la Fuente, J. Anaplasmosis: What we can learn from Lam's surrealistic animalarium. Hektoen International Hektorama-Infectious Diseases-Summer. 2018. Available online: http://hekint.org/2018/08/23/anasplasmosiswhat-we-can-learn-from-lams-surrealistic-animalarium/ (accessed on 1 August 2019).

8. Riego, E.; Silva, A.; de la Fuente, J. The sound of the DNA language. Biol. Res. 1995, 28, 197-204. [PubMed]

9. Eldred, S.M. Art-science collaborations: Change of perspective. Nature 2016, 537, 125-126. [CrossRef]

10. Shelton, J. A visual artist compares the way scientists and artists see a world of discovery. YaleNews. 3 April 2017. Available online: https://news.yale.edu/2017/04/03/visual-artist-compares-way-scientists-and-artistssee-world-discovery (accessed on 1 August 2019).

11. Maeda, J. Artists and scientists: More alike than different. Scientific American. 11 July 2013. Available online: https://blogs.scientificamerican.com/guest-blog/artists-and-scientists-more-alike-than-different/ (accessed on 1 August 2019).

12. Peña-Rangel, M.T.; Rodriguez, I.; Riesgo-Escovar, J.R. A misexpression study examining dorsal thorax formation in Drosophila melanogaster. Genetics 2002, 160, 1035-1050.

13. Almazán, C.; Kocan, K.M.; Bergman, D.K.; Garcia-Garcia, J.C.; Blouin, E.F.; de la Fuente, J. Identification of protective antigens for the control of Ixodes scapularis infestations using cDNA expression library immunization. Vaccine 2003, 21, 1492-1501. [CrossRef]

14. DasGupta, R.; Kaykas, A.; Moon, R.T.; Perrimon, N. Functional genomic analysis of the Wnt-wingless signaling pathway. Science 2005, 308, 826-833. [CrossRef]

15. Goto, A.; Matsushita, K.; Gesellchen, V.; El Chamy, L.; Kuttenkeuler, D.; Takeuchi, O.; Hoffmann, J.A.; Akira, S.; Boutros, M.; Reichhart, J.M. Akirins are highly conserved nuclear proteins required for NF-kappaB-dependent gene expression in Drosophila and mice. Nat. Immunol. 2008, 9, 97-104. [CrossRef]

16. Macqueen, D.J.; Johnston, I.A. Evolution of the multifaceted eukaryotic akirin gene family. BMC Evol. Biol. 2009, 9, 34. [CrossRef]

17. Artigas-Jerónimo, S.; Villar, M.; Cabezas-Cruz, A.; Valdés, J.J.; Estrada-Peña, A.; Alberdi, P.; de la Fuente, J. Functional evolution of Subolesin/Akirin. Front. Physiol. 2018, 9, 1612. [CrossRef] [PubMed]

18. Polanowska, J.; Chen, J.X.; Soulé, J.; Omi, S.; Belougne, J.; Taffoni, C.; Pujol, N.; Selbach, M.; Zugasti, O.; Ewbank, J.J. Evolutionary plasticity in the innate immune function of Akirin. PLoS Genet. 2018, 14, e1007494. [CrossRef]

19. Rual, J.F.; Venkatesan, K.; Hao, T.; Hirozane-Kishikawa, T.; Dricot, A.; Li, N.; Berriz, G.F.; Gibbons, F.D.; Dreze, M.; Ayivi-Guedehoussou, N.; et al. Towards a proteome-scale map of the human protein-protein interaction network. Nature 2005, 437, 1173-1178. [CrossRef] [PubMed]

20. Abdelmohsen, K.; Srikantan, S.; Yang, X.; Lal, A.; Kim, H.H.; Kuwano, Y.; Galban, S.; Becker, K.G.; Kamara, D.; de Cabo, R.; et al. Ubiquitin-mediated proteolysis of HuR by heat shock. EMBO J. 2009, 28, 1271-1282. [CrossRef] [PubMed]

21. Armour, S.M.; Bennett, E.J.; Braun, C.R.; Zhang, X.Y.; McMahon, S.B.; Gygi, S.P.; Harper, J.W.; Sinclair, D.A. A high-confidence interaction map identifies SIRT1 as a mediator of acetylation of USP22 and the SAGA coactivator complex. Mol. Cell. Biol. 2013, 33, 1487-1502. [CrossRef] [PubMed] 
22. Hein, M.Y.; Hubner, N.C.; Poser, I.; Cox, J.; Nagaraj, N.; Toyoda, Y.; Gak, I.A.; Weisswange, I.; Mansfeld, J.; Buchholz, F.; et al. A human interactome in three quantitative dimensions organized by stoichiometries and abundances. Cell 2015, 163, 712-723. [CrossRef]

23. Huttlin, E.L.; Bruckner, R.J.; Paulo, J.A.; Cannon, J.R.; Ting, L.; Baltier, K.; Colby, G.; Gebreab, F.; Gygi, M.P.; Parzen, H.; et al. Harper, architecture of the human interactome defines protein communities and disease networks. Nature 2017, 545, 505-509. [CrossRef]

24. de la Fuente, J.; Maritz-Olivier, C.; Naranjo, V.; Ayoubi, P.; Nijhof, A.M.; Almazán, C.; Canales, M.; Pérez de la Lastra, J.M.; Galindo, R.C.; Blouin, E.F.; et al. Evidence of the role of tick subolesin in gene expression. BMC Genom. 2008, 9, 372. [CrossRef] [PubMed]

25. Nowak, S.J.; Baylies, M.K. Akirin: A context-dependent link between transcription and chromatin remodeling. Bioarchitecture 2012, 2, 209-213. [CrossRef]

26. Goto, A.; Fukuyama, H.; Imler, J.L.; Hoffmann, J.A. The chromatin regulator DMAP1 modulates activity of the nuclear factor B (NF-B) transcription factor Relish in the Drosophila innate immune response. J. Biol. Chem. 2014, 289, 20470-20476. [CrossRef]

27. Bonnay, F.; Nguyen, X.H.; Cohen-Berros, E.; Troxler, L.; Batsche, E.; Camonis, J.; Takeuchi, O.; Reichhart, J.M.; Matt, N. Akirin specifies NF- $\mathrm{BB}$ selectivity of Drosophila innate immune response via chromatin remodeling. EMBO J. 2014, 33, 2349-2362. [CrossRef] [PubMed]

28. Shaw, D.K.; Wang, X.; Brown, L.J.; Chávez, A.S.; Reif, K.E.; Smith, A.A.; Scott, A.J.; McClure, E.E.; Boradia, V.M.; Hammond, H.L.; et al. Infection-derived lipids elicit an immune deficiency circuit in arthropods. Nat. Commun. 2017, 8, 14401. [CrossRef] [PubMed]

29. de la Fuente, J.; Kopáček, P.; Lew-Tabor, A.; Maritz-Olivier, C. Strategies for new and improved vaccines against ticks and tick-borne diseases. Parasite Immunol. 2016, 38, 754-769. [CrossRef] [PubMed]

30. Camnitzer, L. New Art of Cuba; University of Texas Press: Austin, TX, USA, 1994.

31. Cordero, R. Raúl Cordero; Turner: Madrid, Spain, 2010.

32. Formstecher, E.; Aresta, S.; Collura, V.; Hamburger, A.; Meil, A.; Trehin, A.; Reverdy, C.; Betin, V.; Maire, S.; Brun, C.; et al. Protein interaction mapping: A Drosophila case study. Genome Res. 2005, 15, 376-384. [CrossRef] [PubMed]

33. Rain, J.C.; Selig, L.; De Reuse, H.; Battaglia, V.; Reverdy, C.; Simon, S.; Lenzen, G.; Petel, F.; Wojcik, J.; Schächter, V.; et al. The protein-protein interaction map of Helicobacter pylori. Nature 2011, 409, 211-215. [CrossRef] [PubMed]

34. Moreno-Cid, J.A.; Pérez de la Lastra, J.M.; Villar, M.; Jiménez, M.; Pinal, R.; Estrada-Peña, A.; Molina, R.; Lucientes, J.; Gortázar, C.; de la Fuente, J. SUB/AKR Vaccine Study Group. Control of multiple arthropod vector infestations with subolesin/akirin vaccines. Vaccine 2013, 31, 1187-1196. [CrossRef]

35. Merino, O.; Antunes, S.; Mosqueda, J.; Moreno-Cid, J.A.; Pérez de la Lastra, J.M.; Rosario-Cruz, R.; Rodríguez, S.; Domingos, A.; de la Fuente, J. Vaccination with proteins involved in tick-pathogen interactions reduces vector infestations and pathogen infection. Vaccine 2013, 31, 5889-5896. [CrossRef]

36. Garcia-Garcia, J.; Valls-Comamala, V.; Guney, E.; Andreu, D.; Muñoz, F.J.; Fernandez-Fuentes, N.; Oliva, B. iFrag: A protein-protein interface prediction server based on sequence fragments. J. Mol. Biol. 2017, 429, 382-389. [CrossRef]

37. Ayllón, N.; Villar, M.; Busby, A.T.; Kocan, K.M.; Blouin, E.F.; Bonzón-Kulichenko, E.; Galindo, R.C.; Mangold, A.J.; Alberdi, P.; Pérez de la Lastra, J.M.; et al. Anaplasma phagocytophilum inhibits apoptosis and promotes cytoskeleton rearrangement for infection of tick cells. Infect. Immun. 2013, 81, 2415-2425. [CrossRef]

38. Prudencio, C.R.; Pérez de la Lastra, J.M.; Canales, M.; Villar, M.; de la Fuente, J. Mapping protective epitopes in the tick and mosquito subolesin ortholog proteins. Vaccine 2010, 28, 5398-5406. [CrossRef]

39. Ward, J.J.; Sodhi, J.S.; McGuffin, L.J.; Buxton, B.F.; Jones, D.T. Prediction and functional analysis of native disorder in proteins from the three kingdoms of life. J. Mol. Biol. 2004, 337, 635-645. [CrossRef]

40. Kim, D.E.; Chivian, D.; Baker, D. Protein structure prediction and analysis using the Robetta server. Nucleic Acids Res. 2004, 32, W526-W531. [CrossRef]

41. Zhang, Y. I-TASSER server for protein 3D structure prediction. BMC Bioinform. 2008, 9, 40. [CrossRef]

42. Wu, S.; Zhang, Y. LOMETS: A local meta-threading-server for protein structure prediction. Nucleic Acids Res. 2007, 35, 3375-3382. [CrossRef] 
43. Benkert, P.; Kunzli, M.; Schwede, T. QMEAN server for protein model quality estimation. Nucleic Acids Res. 2009, 37, W510-W514. [CrossRef]

44. Wingelhofer, B.; Neubauer, H.A.; Valent, P.; Han, X.; Constantinescu, S.N.; Gunning, P.T.; Müller, M.; Moriggl, R. Implications of STAT3 and STAT5 signaling on gene regulation and chromatin remodeling in hematopoietic cancer. Leukemia 2018, 32, 1713-1726. [CrossRef]

45. van Essen, D.; Engist, B.; Natoli, G.; Saccani, S. Two modes of transcriptional activation at native promoters by NF-kappaB p65. PLoS Biol. 2009, 7, e73. [CrossRef]

46. Tieri, P.; Termanini, A.; Bellavista, E.; Salvioli, S.; Capri, M.; Franceschi, C. Charting the NF-kB pathway interactome map. PLoS ONE 2012, 7, e32678. [CrossRef]

47. Joly, S.; Rhea, L.; Volk, P.; Moreland, J.G.; Dunnwald, M. Interferon regulatory factor 6 has a protective role in the host response to endotoxic shock. PLoS ONE 2016, 11, e0152385. [CrossRef]

48. Pranski, E.L.; Dalal, N.V.; Herskowitz, J.H.; Orr, A.L.; Roesch, L.A.; Fritz, J.J.; Heilman, C.; Lah, J.J.; Levey, A.I.; Betarbet, R.S. Neuronal RING finger protein 11 (RNF11) regulates canonical NF-кB signaling. J. Neuroinflamm. 2012, 9, 67. [CrossRef]

49. Frasor, J.; El-Shennawy, L.; Stender, J.D.; Kastrati, I. NFkB affects estrogen receptor expression and activity in breast cancer through multiple mechanisms. Mol. Cell. Endocrinol. 2015, 418 Pt 3, 235-239. [CrossRef]

50. Du, Q.; Geller, D.A. Cross-regulation between Wnt and NF- $\mathrm{B}$ signaling pathways. For Immunopathol. Dis. Therap. 2010, 1, 155-181. [CrossRef] [PubMed]

51. Hoffmann, A.; Baltimore, D. Circuitry of nuclear factor kappaB signaling. Immunol. Rev. 2006, 210, 171-186. [CrossRef] [PubMed]

52. de la Garza, G.; Schleiffarth, J.R.; Dunnwald, M.; Mankad, A.; Weirather, J.L.; Bonde, G.; Butcher, S.; Mansour, T.A.; Kousa, Y.A.; Fukazawa, C.F.; et al. Interferon regulatory factor 6 promotes differentiation of the periderm by activating expression of Grainyhead-like 3. J. Investig. Dermatol. 2013, 133, 68-77. [CrossRef]

53. Kowalec, K.; Wright, G.E.B.; Drögemöller, B.I.; Aminkeng, F.; Bhavsar, A.P.; Kingwell, E.; Yoshida, E.M.; Traboulsee, A.; Marrie, R.A.; Kremenchutzky, M.; et al. Common variation near IRF6 is associated with IFN- $\beta$-induced liver injury in multiple sclerosis. Nat. Genet. 2018, 50, 1081-1085. [CrossRef]

54. Lenardo, M.J.; Fan, C.M.; Maniatis, T.; Baltimore, D. The involvement of NF- $\kappa B$ in $\beta$-interferon gene regulation reveals its role as widely inducible mediator of signal transduction. Cell 1989, 57, 287-294. [CrossRef]

55. MacDonald, N.J.; Kuhl, D.; Maguire, D.; Näf, D.; Gallant, P.; Goswamy, A.; Hug, H.; Büeler, H.; Chaturvedi, M.; de la Fuente, J.; et al. Different pathways mediate virus inducibility of the human IFN-alpha1 and IFN-beta genes. Cell 1990, 60, 767-779. [CrossRef]

56. Hiscott, J.; Alper, D.; Cohen, L.; Leblanc, J.F.; Sportza, L.; Wong, A.; Xanthoudakis, S. Induction of human interferon gene expression is associated with a nuclear factor that interacts with the NF-kappa B site of the human immunodeficiency virus enhancer. J. Virol. 1989, 63, 2557-2566. [CrossRef]

57. Sharif, O.; Bolshakov, V.N.; Raines, S.; Newham, P.; Perkins, N.D. Transcriptional profiling of the LPS induced NF-kB response in macrophages. BMC Immunol. 2007, 8, 1471-2172. [CrossRef]

58. Sheikh, F.; Dickensheets, H.; Gamero, A.M.; Vogel, S.N.; Donnelly, R.P. An essential role for IFN- $\beta$ in the induction of IFN-stimulated gene expression by LPS in macrophages. J. Leukoc. Biol. 2014, 96, 591-600. [CrossRef]

59. Ashdown, H.; Dumont, Y.; Ng, M.; Poole, S.; Boksa, P.; Luheshi, G.N. The role of cytokines in mediating effects of prenatal infection on the fetus: Implications for schizophrenia. Mol. Psychiatry 2006, 11, 47-55. [CrossRef] [PubMed]

60. Sakai, J.; Cammarota, E.; Wright, J.A.; Cicuta, P.; Gottschalk, R.A.; Li, N.; Fraser, I.D.C.; Bryant, C.E. Lipopolysaccharide-induced NF-kB nuclear translocation is primarily dependent on MyD88, but TNF $\alpha$ expression requires TRIF and MyD88. Sci Rep. 2017, 7, 1428. [CrossRef]

61. Contreras, M.; de la Fuente, J. Control of Ixodes ricinus and Dermacentor reticulatus tick infestations in rabbits vaccinated with the Q38 Subolesin/Akirin chimera. Vaccine 2016, 34, 3010-3013. [CrossRef]

62. Ailenberg, M.; Rotstein, O. An improved Huffman coding method for archiving text, images, and music characters in DNA. Biotechniques 2009, 47, 747-754. [CrossRef]

63. Temple, M.D. An auditory display tool for DNA sequence analysis. BMC Bioinform. 2017, 18, 221. [CrossRef]

64. Mannone, M. Knots, music and DNA. J. Creat. Music Syst. 2018, 2, 32. [CrossRef]

65. de la Fuente, J.; Estrada-Peña, A. Why new vaccines for the control of ectoparasite vectors have not been registered and commercialized? Vaccines 2019, 7, 75. [CrossRef] 
66. de la Fuente, J.; Moreno-Cid, J.A.; Canales, M.; Villar, M.; Pérez de la Lastra, J.M.; Kocan, K.M.; Galindo, R.C.; Almazán, C.; Blouin, E.F. Targeting arthropod subolesin/akirin for the development of a universal vaccine for control of vector infestations and pathogen transmission. Vet. Parasitol. 2011, 181, 17-22. [CrossRef]

67. de la Fuente, J.; Moreno-Cid, J.A.; Galindo, R.C.; Almazán, C.; Kocan, K.M.; Merino, O.; Pérez de la Lastra, J.M.; Estrada-Peña, A.; Blouin, E.F. Subolesin/Akirin vaccines for the control of arthropod vectors and vector-borne pathogens. Transbound. Emerg. Dis. 2013, 60 (Suppl. 2), 172-178. [CrossRef]

68. de la Fuente, J.; Merino, O. Vaccinomics, the new road to tick vaccines. Vaccine 2013, 31, 5923-5929. [CrossRef]

69. Contreras, M.; Villar, M.; de la Fuente, J. A vaccinomics approach to the identification of tick protective antigens for the control of Ixodes ricinus and Dermacentor reticulatus infestations in companion animals. Front. Physiol. 2019, 10, 977. [CrossRef] [PubMed]

70. Artigas-Jerónimo, S.; Estrada-Peña, A.; Cabezas-Cruz, A.; Alberdi, P.; Villar, M.; de la Fuente, J. Modeling modulation of the tick regulome in response to Anaplasma phagocytophilum for the identification of new control targets. Front. Physiol. 2019, 10, 462. [CrossRef] [PubMed]

71. de la Fuente, J.; Villar, M.; Estrada-Peña, A.; Olivas, J.A. High throughput discovery and characterization of tick and pathogen vaccine protective antigens using vaccinomics with intelligent Big Data analytic techniques. Expert Rev. Vaccines 2018, 17, 569-576. [CrossRef]

(C) 2020 by the authors. Licensee MDPI, Basel, Switzerland. This article is an open access article distributed under the terms and conditions of the Creative Commons Attribution (CC BY) license (http://creativecommons.org/licenses/by/4.0/). 